BULLETIN Bulletin hispanique

HISPANIQUE Université Michel de Montaigne Bordeaux

112-1| 2010

Actes du Colloque « langue, littérature, littéralité »

\title{
La traduction des archaïsmes du Don Quichotte
}

Jean-Claude Chevalier et Marie-France Delport

\section{OpenEdition}

Journals

Édition électronique

URL : http://journals.openedition.org/bulletinhispanique/1761

DOI : 10.4000/bulletinhispanique. 1761

ISSN : 1775-3821

\section{Éditeur}

Presses universitaires de Bordeaux

\section{Édition imprimée}

Date de publication : 1 juin 2010

Pagination : 221-274

ISBN : 978-2-86781-692-5

ISSN : 0007-4640

Référence électronique

Jean-Claude Chevalier et Marie-France Delport, "La traduction des archaïsmes du Don Quichotte ", Bulletin hispanique [En ligne], 112-1 | 2010, mis en ligne le 01 juin 2013, consulté le 01 mai 2019. URL: http://journals.openedition.org/bulletinhispanique/1761; DOI : 10.4000/bulletinhispanique.1761

Ce document a été généré automatiquement le 1 mai 2019.

Tous droits réservés 


\title{
La traduction des archaïsmes du Don Quichotte
}

\author{
Jean-Claude Chevalier et Marie-France Delport
}

1 Les œuvres du passé - les œuvres littéraires s'entend - sont toutes des archaïsmes. À pareille affirmation on se récrie le plus souvent. Elle scandalise parfois. C'est qu'on dispose, et depuis longtemps, de formules qui permettent de s'y opposer et auxquelles on ajoute le crédit le plus aveugle. Combien d'œuvres du passé "sont encore vivantes »! Combien «sont encore d'aujourd'hui»! Combien "nous parlent comme si elles étaient d'hier»! Allons plus loin : combien "sont éternelles»! Et de toutes ces expressions, ressassées ou enjolivées, nous nous faisons un écran. Nous refusons de voir que les œuvres du passé sont écrites dans une langue qui n'est plus la nôtre - c'est évident !-, qu'elles sont faites d'un lexique, d'une syntaxe, d'une morphologie parfois qui n'ont plus cours. Ou plutôt nous le voyons, nous l'entrevoyons mais tenons que c'est sans importance. Qu'au-dessus de cet obstacle, et qui le rend transparent, qui le transcende, il y a quelque chose d'intemporel. Quelque chose d'intemporel qui seul mérite attention, respect et admiration ; qui seul appelle l'analyse. Or, cet archaïsme linguistique, qu'on le veuille ou non, ne peut être effacé. Il crée une distance entre l'œuvre et le lecteur d'aujourd'hui. Une distance qu'on ne peut plus abolir sans, du même coup, abolir l'œuvre. Car elle en fait partie désormais, au point que, pour plusieurs, elle participe à son charme et à l'intérêt qu'on y prend, même si, pour quelques-uns, elle peut être une gêne ou une entrave.

On devine tout de suite ce qui en résulte pour le traducteur. Cette distance devenue consubstantielle à l'œuvre, il lui faut décider s'il la conservera, et dans quelle mesure. S'il la traduira, s'il prendra le parti de l'œuvre ou celui du plus paresseux des lecteurs de sa traduction, son contemporain. Il y a là une difficulté qui, au cours de l'histoire (et aujourd'hui encore), a reçu diverses solutions. Mais la difficulté s'augmente lorsqu'une autre distance s'inscrit - et explicitement - dans l'œuvre elle-même, sensible et évidente dès le temps de sa publication. Car, pour le lecteur d'aujourd'hui, c'est en ce cas une double distance qu'emporte l'œuvre : celle qui fut présente au jour de sa naissance pour tous ses contemporains et celle qui, avec les siècles, s'est installée inévitablement. Certes, 
la première est un morceau de l'œuvre et a pour origine la volonté délibérée de l'auteur, quand la seconde est née du temps qui passe et a sa source dans le lecteur. Mais les deux, prenons garde, reçoivent une matérialisation linguistique. Et c'est à quoi est confronté le traducteur.

Le Don Quichotte de Cervantès en offre la meilleure illustration. Pour le lecteur espagnol de 1605 ou de 1615, l'œuvre est écrite dans une langue qui est la sienne. La sienne pliée aux habitudes stylistiques de Cervantès, mais la sienne tout de même : il y reconnaît tous les tours dont il a l'usage. Aucun effet de distance donc entre la façon de conter, plus exactement entre la langue utilisée et celle du consommateur de l'œuvre. Auteur et lecteur partagent ici le même instrument. Mais il se trouve qu'un personnage (don Quichotte) et quelques autres, épisodiquement, qui l'imitent dans leurs réponses ou lorsqu'ils parlent de lui, recourent à une langue qui, en 1605 ou 1615, est totalement caduque. Pour des effets divers, le plus souvent comiques ou ridicules, décalés de toute façon, ce sont des vocables, des syntaxes, des prononciations désuètes, ou même oubliées, qui sont mises en œuvre. Pour le lecteur du Siècle d'Or, et par moyen de langage, une distance est donc ainsi inscrite entre lui-même et un temps révolu. Mais pour le lecteur espagnol d'aujourd'hui vient s'y ajouter celle que quatre siècles ont mise entre le castillan de Cervantès et celui d'à présent. Le Don Quichotte, pour lui, est donc une œuvre à double fond ; et ce double fond n'est pas seulement - n'est pas primordialement - celui des comportements, celui des idées, celui des êtres et des objets mis en scène dans le roman, mais celui de la langue. Et, autant que l'on puisse encore le constater, au lecteur moderne de l'original il n'est guère besoin, pour être sensible à cet état de choses, d'une culture de philologue ou d'un savoir bien élaboré. Un peu d'attention lui suffit. Il perçoit à chaque page que l'œuvre est d'un passé lointain et le parler du héros, en plusieurs occasions, d'un passé plus lointain encore.

4 Cette duplicité chronique, cette double profondeur temporelle et le rôle qu'elle a fini par tenir dans la perception que l'on se donne aujourd'hui de l'œuvre, nulle part peut-être ne se laissent-ils mieux apercevoir que dans les traductions. Il suffit que l'une ou l'autre des distances que l'on vient de signaler soit gommée, ou altérée de quelque façon, pour que l'œuvre en soit modifiée dans sa nature, dans sa signification, dans ses effets. La tentation est toujours forte chez le traducteur d'amener à soi l'œuvre du passé, à soi et au lecteur visé. Il «dépoussière ", il «ravive", il «revisite», il procède à "un rajeunissement discret $»^{1}$; bref, il « modernise » : c'est sa revendication. C'est, en fait, l'écart du castillan de 1605 à celui d'aujourd'hui qui en pâtit. On répondra que, moyennant quelque gente dame, quelque moult, quelque icelle ou iceluy introduits dans le discours de don Quichotte, on aura conservé celui qu'a voulu Cervantès. Celui seulement qui était servi au lecteur d'autrefois. C'est se contenter de peu et donner à voir un plan là où, pour le lecteur d'aujourd'hui qui a accès à l'original, il y en a deux. Mais il est bon de regarder de plus près.

\section{Les archaïsmes de l'espagnol de 1605}

5 Considérons d'abord, avant ceux du personnage de don Quichotte, les « archaïsmes » de Cervantès, les « archaïsmes » de l'espagnol qui était le sien - qui était celui de son temps. Et ici entendons-nous bien. Il existe dans le Don Quichotte, comme dans toute œuvre de l'époque, des séquences qui pourraient être d'aujourd'hui. Rien en elles que ne pourrait admettre l'espagnol du XXI e siècle. Observons seulement que "l'impression d'actualité » 
ne tient qu'autant que l'on isole ces séquences, qu'on les arrache à l'ensemble auquel elles appartiennent. Leur "archaïsme » tient donc à ce qu'elles coexistent avec d'autres qui sont hors d'usage désormais : c'est de cette compatibilité de ce qui n'est plus possible et de ce qui l'est encore que l'on tirait, en commençant, l'affirmation péremptoire que dans les œuvres du passé « tout est archaïque ». Mais, dans ce qui par soi (sans son entourage) suffit à l'être, il faut encore faire une distinction : d'un côté l'on a les signifiants qui n'ont plus cours, sortis de la mémoire de tous, et de l'autre ceux que l'on connaît encore - ou croit connaître - mais dont le signifié, ou la référence, a varié. Il n'est pas sûr que tous les traducteurs s'en soient toujours avisés ou aient jugé qu'il en fallait tenir compte.

\section{Le nom du héros}

6 Le nom du héros en est un premier exemple, et fort éclairant. La première fois qu'il en est question il est dit :

Quieren decir que tenía el sobrenombre de Quijada ó Quesada, que en esto hay alguna diferencia en los autores que deste caso escriben; aunque por conjeturas verosímiles se deja entender que se llamaba Quijana.

(Clásicos Castellanos, Madrid, 1964, t. I, p. 52)

Et quelques pages plus loin:

... al cabo se vino á llamar don Quijote; de donde, como queda dicho, tomaron ocasión los autores desta tan verdadera historia que, sin duda, se debía de llamar Quijada, y no Quesada, como otros quisieron decir.

(Ibid., p. 62)

7 Dans cette orthographe, qui depuis près d'un siècle et demi est celle des éditions courantes, et avec la prononciation qu'elle induit (articulation vélaire dans Quijada et Quijote comme dans conjeturas et dejar), le bien-fondé de la déduction signalée (de donde, como queda dicho, tomaron ocasión...) s'entend sans peine: si notre héros se baptise luimême Quijote (avec jota), il y a quelque vraisemblance à lui supposer pour nom réel Quijada (avec jota). Mais c'est l'hésitation, Quijada ou Quesada, pour peu qu'on ait de l'oreille, qui laisse perplexe: si l'on peut avoir des doutes sur la voyelle que l'on a entendue ( $i$ ou $e$ ?), balance-t-on vraiment entre une fricative vélaire $([x])$ et une fricative apico-alvéolaire ( $[s])$ ? Les confusions - ou les risques de confusion -, en ces occurrenceslà, se font toujours au plus près: le mode d'articulation est identique, le point d'articulation doit être voisin. Il y a donc fort à parier que, si la prononciation de Cervantès avait été celle qu'invite à adopter cette graphie modernisée (j pour $x)$, il n'eût pas choisi pour noms possibles de son héros Quijada et Quesada, non plus que Quijana, comme il est malicieusement suggéré plus loin. Par où l'on voit, pour un lecteur un peu exigeant, les conséquences désastreuses d'une simple modernisation graphique: elle introduit de l'incohérence où il n'y en avait point. Observons, par parenthèse, que, dans un premier temps, pour le lecteur espagnol d'aujourd'hui, les dégâts seraient moindres si l'on conservait la forme originale avec $-x-:$ cet $-x-$, il y a de fortes chances pour que, sans ultracorrection ( $[k s]$ ), il l'articule comme dans examen ou exigir, i. e. avec une fricative apico-alvéolaire sourde; et l'incertitude Quixada / Quesada ne portant que sur le degré d'aperture de la voyelle, lui paraîtrait recevable. Reste que, dans un deuxième temps, l'inférence Quixote / Quixada, une fois de plus, ne lui semblerait pas aller de soi. Car ce don Quixote, tout armé qu'il soit de son - $x-$, il lui serait difficile de le prononcer sans vélaire. Sans savoir préalable, il n'irait pas contre une tradition qui a plus de trois siècles et fait de 
don Quijote (avec jota prononcée, quelle que soit la graphie) le nom d'un héros universellement connu.

La cohérence du texte de Cervantès, on ne le sait que trop, repose sur le code graphique de son temps: par la lettre $-\chi$ - se traduisait alors une fricative sourde palatale ${ }^{2}$. De là l'hésitation que l'on pouvait avoir ${ }^{3}$ sur le sobrenombre du héros. Les manuscrits de l'époque attestent du reste qu'elle n'était pas rare ${ }^{4}:$ simio ximio, sastre $\sim$ xastre, cessar cexar, Quessada $\sim$ quixada ${ }^{5}$, vessiga $\sim$ vexiga, mascara $\sim$ maxcara $^{6}$. Cervantès ici n'inventait rien ; il enregistrait une pratique.

On en a assez dit pour que l'on mesure tout de suite la difficulté qui s'offrait aux traducteurs. On n'en considérera que neuf, et tous français (voir Annexes). La séquence des patronymes, en chacun des cas, est éloquente et témoigne d'une attention inégale ou d'une exigence plus ou moins relâchée :

1 a - Quixada - Quesada - Quixana / Quichotte - Quixade - Quesada

1 b-Quixada - Quésada - Quixada / Quichotte - $\varnothing$

1 c - Quixada - Quesada - Quijana / Quichotte - Quixada - Quesada

$1 \mathrm{~d}$ - Quijada - Quesada - Quijana / Quichotte - Quijada - Quesada

1 e - Quijada - Quesada - Quejana / Quichotte - Quijada - Quesada

$1 \mathrm{f}$ - Quichada - Quesada - Quechana / Quichotte - Quichada - Quesada

$1 \mathrm{~g}$ - Quijada - Quesada - Quijana / Quichotte - Quijada - Quesada

$1 \mathrm{~h}$ - Quichada - Quesada - Quichana / Quichotte - Quichada - Quesada

1 i - Quixada - Quesada - Quixana / Quichotte - Quixade - Quesada

Deux parmi les traducteurs les plus récents $(1 f$ et $1 h)$ mettent - ch - où était - $x-$, ce qui, au moment de la déduction, est irréprochable : le bonhomme a choisi de « se nommer don Quichotte» et on est en droit d'en "tirer argument pour dire qu'il devait s'appeler Quichada». Quant à la distance qu'il y a de la fricative palatale (-ch- de Quichada) à la fricative dorso-alvéolaire (-s- de Quesada), il suffit au lecteur français de penser à quelque Auvergnat ou à l'une de ses connaissances qui a le travers de «chuinter " pour admettre l'indécision où l'on était sur le vrai nom du héros. Encore qu'il faille chez ce lecteur français supposer un savoir qu'il n'a pas toujours : supposer que, à l'espagnole, il conserve la sourdité $\mathrm{du}-s$ - intervocalique. Articulé à la française, ce -s- en effet est sonore et la distance de [ $\left.\int\right]$ (Quichada) à [ $z$ ] (Quesada) s'en trouve accrue et l'hésitation sur le nom moins vraisemblable.

11 La traduction la plus ancienne, mais révisée par Cassou (1 a), n'avait pas cette cohérence : elle conserve trois fois l'orthographe de l'espagnol de $1605(-x-)$ mais choisit d'écrire Quichotte. Peut-on imaginer qu'un lecteur français, à quelque époque qu'on veuille le placer, puisse comprendre que de Quichotte on conclue à Quixada? Il faudrait lui prêter l'idée plus qu'improbable que - $x$ - et -ch- ont même prononciation. Et, de surcroitt, que [ks] et $[s]$ ont des articulations assez voisines pour devenir imprécises au point qu'on les confonde. C'est trop attendre de lui. Le - $e$ final de Quixade, $-e$ qu'il partage avec Quichotte, est peut-être une coquille. S'il ne l'est, il n'en demeure pas moins insuffisant : ce n'est pas lui qui justifiera la déduction des " auteurs de cette tant véritable histoire ». Outre que Quixade ne reprend plus Quixada antérieurement supposé et ajoute inutilement à la liste des noms possibles.

12 Avec Florian ( $1 b)$ la cause est vite entendue. Il ne semble pas avoir fait grand cas de ces affaires de nom. Un, il se dispense de traduire la déduction : il signale que le héros «se nomma don Quichotte » et passe à autre chose. Il coupe court à ces histoires de supposés 
auteurs qui auraient disserté sur la réalité et sur le vrai. Deux, lorsque, à la première fois, il leur prête l'oreille, c'est pour éviter la malice du narrateur - autre auteur donc qui a son propre avis sur le sujet puisqu'il en tient, lui, pour Quixana. On francisera en portant un accent sur le - $e$ - de Quesada. Pas de troisième possibilité. On ne peut faire plus simple et moins significatif. Il est vrai que si l'on annonce "Traduit de Michel de Cervantes », le volume est intitulé «Le Don Quichotte de la jeunesse ». Toutes les simplifications, de ce fait, étaient permises. $\mathrm{Et}-\mathrm{x}$ - ou -ch-perdaient toute importance.

connaissait-il la prononciation espagnole du début du XVII ${ }^{e}$ siècle? Si c'est la raison de la conservation graphique des $-x-$, il n'aidait pas plus le lecteur français du XIX ${ }^{e}$ siècle et des temps qui suivirent, que ne le fera Cassou révisant Oudin : à tous ces $-x$ - fait suite le -ch- de don Quichotte. Il ajoutera même à la difficulté ou à l'incohérence, puisqu'il prête au narrateur, juge des auteurs, une jota : Quijana.

Cardaillac et Labarthe, en 1923, ne sont pas indifférents à la forme des noms propres ( $1 \mathrm{~d}$ ). Ils le déclarent de façon tout explicite : « Nous avons généralement conservé aux noms propres de personnes et de lieux leur orthographe castillane ; il est cependant certains noms pour lesquels, après beaucoup d'hésitations, nous nous sommes résignés à adopter l'orthographe employée dans les traductions françaises, ou celle dont la graphie se rapprochait le plus de la prononciation espagnole à l'époque de Cervantes » (t. 1, p. IX-X). Et ils y reviennent dans une note assez nourrie qu'ils consacrent spécifiquement aux noms du héros. Mais ce n'est que pour s'interroger sur la prononciation $d u-x$ - et ne rien dire de ce qui en découle. Leur texte du reste - et malgré leurs « hésitations » - suit sur ce point les éditions espagnoles de leur temps, et $-j-$, pour les conséquences que l'on sait, paraît chaque fois qu'il y avait $-x-$. Sauf, bien évidemment, dans Quichotte.

Quant à $\mathrm{F}$. de Miomandre ( 1 e), le problème pourrait bien lui avoir échappé. Ou lui avoir paru négligeable. Il suit les éditions espagnoles modernisées (partout un -j-); mais, à leur différence, il va buter sur le-ch- de Quichotte. Les traducteurs $(1 \mathrm{~g})$ de la dernière édition de la Pléiade, qui ont délibérément choisi de ne «franciser les noms des personnages que lorsque l'usage a accrédité cette francisation » (n. 1, p. LXXV), se mettent dans le même pas $^{7}$. Ni la possible hésitation sur les noms ni la déduction ne sont traduites. Tout est perdu.

Et tout aurait pu être conservé ? C'est peut-être ce qu'on aura l'audace de demander. Mais là-dessus il ne doit pas y avoir méprise. Ce serait au prix d'une violence. Au prix de l'abandon de ce que le temps, l'habitude, la tradition, la célébrité et la gloire ont fixé et consacré : Quichotte. C'est au nom du héros et au titre de l'ouvrage qu'il faudrait renoncer. Connaissant ce nom en espagnol (Quixote, avec la fricative palatale), on l'a tout naturellement dès l'origine traduit par Quichotte en français et Chisciotte en italien ${ }^{8}$. Comme aujourd'hui, averti de la prononciation Quijote (avec jota), on aurait sans doute traduit - toujours au plus près - la fricative vélaire espagnole par la vibrante vélaire qu'est notre - $r$ - grasseyé, Quirotte. Notons cependant qu'on ne s'en serait pas mieux trouvé : il aurait été besoin de poser un Quirada et l'on aurait eu plus de peine à faire croire à un doute qui aurait roulé sur Quirada / Quesada ([s] ou [z]). Plus de peine sûrement qu'à l'imaginer, comme en If et $1 \mathrm{~h}$, entre Quichada et Quesada. Mais il y avait Quissotte ou Quéssotte qui, certes, en français ne disent rien s'ils sont de bons voisins phoniques de quizote ou de quezote auxquels Cervantès aurait pu faire appel. Il y a du reste peut-être songé lors du choix de Quixote. La désinence -ote, sans doute ridiculisante, y est comme dans Quixote, et s'y ajoutait le comique qu'il y a à donner à son chevalier errant ou le nom 
d'un poisson, quizote $e^{9}$ ou celui d'un vêtement de bédouin, quezote $e^{10}$. La version française, en ce cas, aurait pu devenir, d'une part :

...et enfin se vint à appeler don Quissotte ; d'où, comme dit est, les auteurs de cette tant véritable histoire ont pris sujet de dire que sans doute il se devait appeler Quissada ou Quessada.

d'autre part :

On veut dire qu'il avait le surnom de Quissada ou Quessada (car en ceci il y a quelque différend entre les auteurs), encore que par conjectures vraisemblables on pense qu'il s'appelait Quissana.

$Y$ aurait-on retrouvé tout ce que Cervantès obtenait avec ses $-x-$ ? Hélas, non. Un peu plus sans doute que par les facilités habituelles des traductions ; mais la dérision qui était dans quixada («La parte ó los huessos de la cabeza del animal, en que estan encaxadas las muelas y dientes» - Aut.) et, par l'intermédiaire de quesadilla («Cierto género de pastel compuesto de queso y massa, que se hace regularmente por carnestolendas » - Aut.), derrière quesada ${ }^{11}$ ne paraît guère. Et puis, répétons-le, Quichotte avec le temps est devenu intouchable.

\section{Le sobrenombre}

18 Autre que cet archaïsme de type grapho-phonique est celui, proprement sémantique, qui porte sur les signifiants dont la signification avec les siècles a varié. Quixada comme Quesada, pour Cervantès, est un sobrenombre. Les risques d'errer pour le lecteur espagnol d'aujourd'hui ne sont sans doute pas nuls. Il arrivera qu'il puisse balancer à comprendre qu'il y a là, visé, ou le nom supplémentaire dont on orne parfois celui des rois et des personnes célèbres ${ }^{12}$ ou le nom de substitution ${ }^{13}$, comique et péjoratif, que chacun peut recevoir. Ces deux acceptions, en effet, figurent dans tous les derniers dictionnaires d'usage ${ }^{14}$. La «mâchoire » qu'il voudra voir derrière Quijada le pousserait vers la seconde. Mais, pour le garder de l'adopter, il a au moins deux raisons de force distincte : il sait, d'une part, que Quesada est un patronyme, et fort répandu, que Quijada a donc toute chance d'être de même espèce ; et, d'autre part, que apodo, en l'occurrence, l'emporte, et de fort loin, sur sobrenombre. Pour s'écarter enfin des deux acceptions à la fois et supposer qu'il y a là un sens de sobrenombre qui est autre, il a, sensible pour lui, le caractère archaïque de tout le texte qu'il lit. Le lecteur français d'aujourd'hui n'a pas, lui, ces gardefous. Surnom, si l'on traduit ainsi, l'oriente tout de suite vers le sobriquet, et, si le texte qu'on lui sert n'est pas d'une langue suffisamment passée pour le mettre en alerte, il a toute chance de s'égarer, de ne pas prendre surnom pour un archaïsme. Surnom, à date classique, disait fort bien sobrenombre. "Nom qu'on adjouste au nom propre, ou au nom de Baptesme. C'est d'ordinaire celuy de la famille, ou d'une seigneurie. Beaucoup de surnoms sont venus de la qualité de la profession, ou du mestier qu'exerçoit celuy qui l'a porté le premier : comme le Fevre, Charpentier, Charron, Meusnier, \&. », écrit Furetière ${ }^{15} \mathrm{du}$ premier ; "El apellido, que se añade despues del nombre propio, que se puso en el Bautismo", écrivent les Autoridades du second ${ }^{16}$. Il ne dépend pas, bien sûr, des traducteurs que ces deux mots aient eu dans leur langue respective des évolutions différentes. Il est permis de penser qu'ils doivent en tenir compte et s'arranger, d'une façon ou d'une autre, pour en tirer les conséquences. que le lecteur français du $\mathrm{XX}^{\mathrm{e}}$ siècle y soit à peu près traité comme le lecteur espagnol. Il y 
trouvait assez de phrases d'allure ancienne, capables de lui mettre la puce à l'oreille et de lui donner à flairer que surnom n'était pas ici à recevoir comme son premier mouvement l'aurait voulu. Lexique, morphologie et toutes les constructions, plus ou moins, y tiennent ce rôle : quelque différend mis pour alguna diferencia, en là où dans était attendu, icelui, puis on ne sorte un seul point de la vérité conduisent sans doute à étendre jusqu'à surnom le même étonnement ou le même dépaysement. À prendre, en somme, pour le considérer la bonne distance.

C'est sans doute ce que ne permettait plus la traduction du XIX siècle ( $1 c)$. De Viardot on peut supposer qu'il ne se méprenait pas sur le sens de sobrenombre quand il le rendait par surnom ; mais déjà ses premiers lecteurs étaient certainement mal armés contre l'erreur ${ }^{17}$. Et ceux qui ont suivi plus encore. Timidement, il y a bien pour les retenir sur le chemin du faux-sens un qui en ont écrit; il faut admettre cependant que des auteurs qui ont quelque divergence et le souci de ne pas s'écarter d'un atome de la vérité tirent dans la direction inverse. Peut-on penser que, quatre-vingt-dix ans plus tard, les traducteurs de $1 d$, avec portait («il portait le surnom...») et, après s'écarter, la répétition conservée de la préposition de ( $\ldots$ ne s'écarte pas d'un point de la vérité »), aient agi autrement et obtenu de meilleurs effets?

Le traducteur du XXe siècle ( $1 e$ e) et le «traducteur » du XVIII $(1 b)$ ne se séparent que sur un l' (l'on / on) : (l') on prétend qu'il avait le surnom de $Q$. Le lecteur du second avait encore dans sa compétence, selon toute probabilité, le moyen d'entendre justement le terme de surnom. Quant au lecteur du premier - et du second s'il s'avisait d'y revenir - toutes les conditions étaient réunies pour qu'il se trompe : sérieux ou réfléchi, il s'étonnera de devoir regarder Quijada et Quesada comme des sobriquets ; pressé ou inattentif, léger ou peu profond, il n'y verra aucune difficulté, ne s'y arrêtera pas. Ainsi l'écriture simple, directe, dépouillée, efficace, désinvolte (Peu importe pourvu que...) du temps des Lumières et le français ordinaire du XXe (n'être pas d'accord sur ce point, ne s'écarter sur aucun point de la vérité) en viennent au même effet.

Malgré des projets différents, mais conscients l'un et l'autre de l'obstacle, deux parmi les derniers traducteurs ( $1 f$ et $1 \mathrm{~h}$ ), se souvenant peut-être de la réponse de Joas dans l'Athalie de Racine ${ }^{18}$, recourent semblablement à avoir nom. Dans la suite de On ne sait pas très bien si $(1 \mathrm{f})$ et à l'imparfait de l'indicatif, il donne soudain une patine de l'ancien temps ; mis au subjonctif passé (qu'il eût nom) (1 h), il est dans son bain. Ce qui est à retenir, c'est que, dans les deux cas, il est répondu à un archaïsme lexical de l'original par un archaïsme idiomatique et que la « faute » est évitée.

\section{Formes verbales en - ra}

2) Desocupado lector, sin juramento me podrás creer que quisiera que este libro, como hijo del entendimiento, fuera el más hermoso, el más gallardo y más discreto que pudiera imaginarse. Pero no he podido yo contravenir á la orden de naturaleza; que en ella cada cosa engendra su semejante. $Y$ así, ¿ qué podía engendrar el estéril y mal cultivado ingenio mío sino la historia de un hijo seco, avellanado, antojadizo, y lleno de pensamientos varios y nunca imaginados de otro alguno...? [...] Sólo quisiera dártela monda y desnuda, sin el ornamento de prólogo, ni de la inumerabilidad y catálogo de los acostumbrados sonetos, epigramas y elogios que al principio de los libros suelen ponerse. Porque te sé decir que, aunque me costó algún trabajo componerla, ninguno tuve por mayor que hacer esta prefación que vas leyendo.

(Ed. Clásicos Castellanos, t. I, p. 7 et p. 9-10.) 
Le prologue de la première partie s'ouvre sur l'expression, à l'adresse de son lecteur, des qualités que l'auteur désire pour son œuvre. C'est un souhait que le lecteur découvre quand le livre est entre ses mains, achevé. Quand les jeux sont faits. L'auteur peut feindre qu'il n'en est rien, que la rédaction du prologue précède celle de l'œuvre elle-même et laisse à celle-ci toutes les chances de déployer les qualités souhaitées. Ou bien choisir la posture de qui juge a posteriori le livre, dresse un bilan, exprime des regrets. Je voudrais, écrira l'auteur adepte de la première attitude. Celui qui, choisissant la seconde, affirme avoir réalisé son projet va retenir, lui aussi, je voudrais s'il entend signifier que le souhait demeure valide. Ce serait privilégier le caractère prospectif du souhait, en optant pour un futur mais en atténuer courtoisement l'urgence puisque ce futur sera un futur du passé. Il pourrait également, et pour plus de déférence encore, s'en tenir à la déclaration du fait d'expérience : je voulais, voire j'avais voulu. Aucune de ces formulations ne préjuge du résultat. L'intention a existé. A-t-elle été suivie d'effet? La suite de la narration le dira peut-être.

Déclarer j'aurais voulu, c'est d'emblée, par l'aspect transcendant, donner à comprendre que le temps du souhait est achevé et que celui-ci, d'incertain, est devenu caduc, irréalisable, hors de toute atteinte.

L'espagnol moderne fait correspondre querría mais aussi quisiera à la première option, quand le souhait n'a pas perdu toute chance de se réaliser. Et habría querido ou, beaucoup plus fréquemment, hubiera querido, à la seconde option, quand le souhait n'est plus qu'un vœu pieux, définitivement périmé.

Les traducteurs semblent avoir hésité à prêter à Cervantès l'une ou l'autre attitude. Seules les trois traductions les plus récentes traduisent semblablement - et par j'aurais voulu chacun des deux quisiera autour desquels s'articulent les paragraphes de l'exemple 2. Le tableau ci-dessous résume ce que l'on trouve développé en annexe.

\begin{tabular}{|l|l|}
\hline \multicolumn{2}{|c|}{ Exemple 2 } \\
\hline a & j'aurais voulu / je voudrais \\
\hline b & je voudrais/ j'aurais désiré \\
\hline c & je voudrais / j'aurais voulu \\
\hline d & je voudrais / j'aurais voulu \\
\hline e & je voudrais / je voudrais \\
\hline f & j'aurais souhaité / j'aurais souhaité \\
\hline g & j'aurais voulu / j'aurais voulu \\
\hline h & j'aurais voulu / j'aurais voulu \\
\hline i & j'eusse désiré / je voudrais \\
\hline
\end{tabular}


L'histoire de la forme en -ra est connue ${ }^{19}$. Elle est issue d'une forme d'indicatif du latin, une forme du parfait et, plus précisément, du passé de ce parfait, laquelle apporte la représentation d'un événement achevé dans le passé. En espagnol, comme dans toutes les langues romanes, l'expression de l'achevé est dévolue aux périphrases dites d'aspect transcendant, en espagnol « haber + participe ». Un mécanisme d'implication, qu'il serait trop long d'expliquer ici $^{20}$, conduit les sujets parlants à faire de la forme en - ra une forme immanente apportant la représentation d'un événement saisi dans son cours, dans son effection, et qui a pour spécificité d'instituer un double repérage et de déclarer qu'un événement prend place dans l'antériorité d'un instant du temps lui-même passé. C'est ce que propose l'exemple 3 dans les vers initiaux :

3) Nunca fuera caballero

De damas tan bien servido

Como fuera don Quijote

Cuando de su aldea vino :

Doncellas curaban dél ;

Princesas, del su rocino.

(Ed. Clásicos Castellanos, t. I, chap. II, p. 84-85)

En figure et très schématiquement :

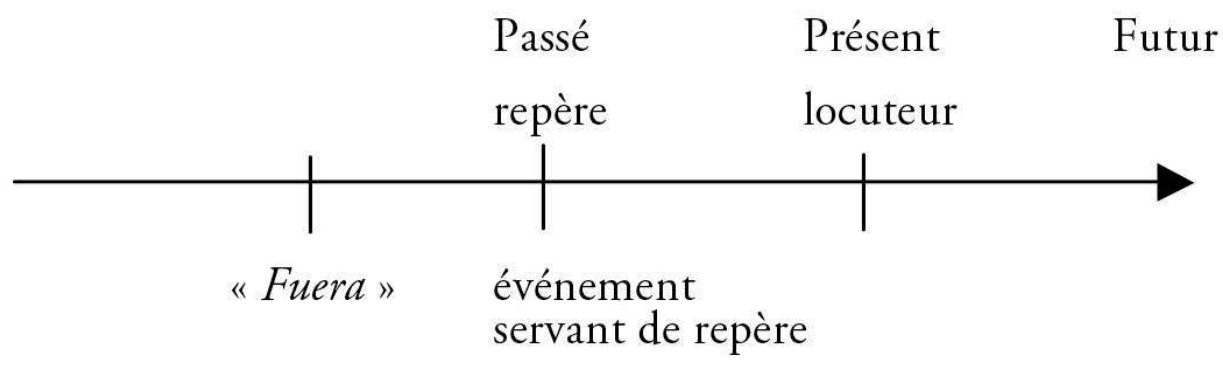

31 Cette forme pouvait entrer en concurrence avec le prétérit (dans l'exemple, on aurait pu rencontrer nunca fue) puisque résultativement elle plaçait un événement dans l'antériorité du présent; il suffisait de renoncer au repérage sur un autre événement passé et de ne retenir que le repérage sur le locuteur :

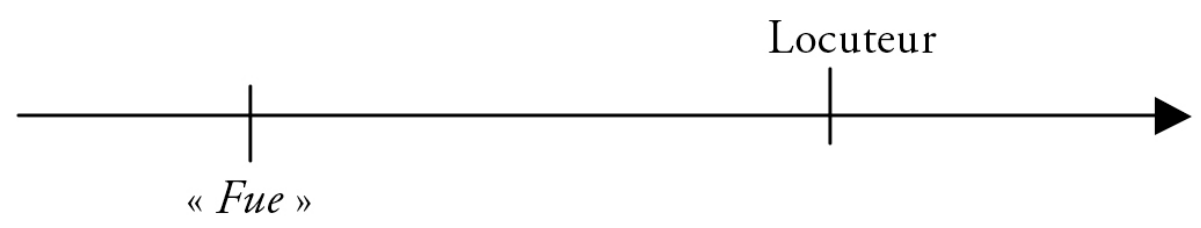

Elle pouvait tout aussi bien alterner avec la forme d'imparfait à l'aspect transcendant (dans l'exemple, nunca había sido), ce que la tradition baptise "plus-que-parfait », lequel place un événement achevé dans l'antériorité du présent, ce qui implique une effection antérieure à ce point du passé : 


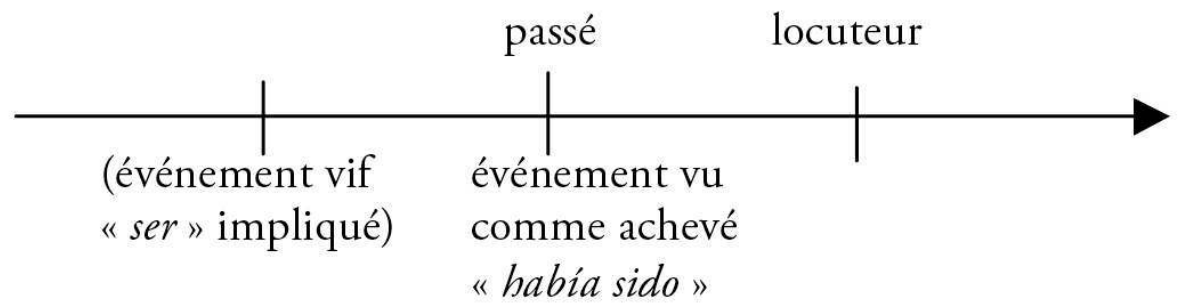

pquées à une matière lexicale qui dit une intention, une capacité, une obligation, bref une modalité de l'action, le prétérit, le plus-que-parfait et, comme eux, la forme en -ra, convenaient à des situations d'expérience où une action effective avait suivi l'intention déclarée aussi bien qu'à des situations où l'intention s'était heurtée à quelque empêchement :

\begin{tabular}{|c|c|c|}
\hline Situation I & & Situation II \\
\hline quise fablar e fablé & / & quise fablar e non lo pude fazer \\
\hline avía querido fablar e fablé & / & avía querido fablar e non lo pude fazer \\
\hline quisiera fablar e fablé & / & quisiera fablar e non lo pude fazer \\
\hline
\end{tabular}

Lorsque se présente la situation II, rien ne s'oppose à ce que le sujet parlant, en français aussi bien qu'en espagnol, au Siècle d'Or comme de nos jours, affirme dans un premier temps que l'intention, la volonté en jeu ici ont existé, pour déclarer, dans un deuxième temps, que cette intention ou cette volonté n'ont pas été suivies d'effet. Plus souvent, cependant, anticipant sur le résultat négatif, le sujet parlant choisit de déclarer d'emblée cette inefficience :j'aurais voulu, dira-t-il en français. Quisiera, en espagnol ancien, hubiera querido par la suite lui ont semblé propres à produire ce même effet. La fréquence d'emploi de la forme en -ra dans des contextes virtualisants - comme l'est celui qui nous occupe - est telle que les locuteurs ont associé ce qui était proprement contextuel à la forme linguistique, invités d'autant plus à le faire que le signifiant de cette forme l'apparentait à des formes par elles-mêmes hypothétiques (quisiese ou quisiere). C'est du moins ainsi qu'on peut expliquer l'évolution observée dans les emplois.

Schématiquement, trois étapes peuvent, de fait, être distinguées dans l'histoire de cette forme.

36

Étape $\mathrm{n}^{\circ} 1$ : la forme est d'abord perçue par les locuteurs comme un passé d'indicatif apte à placer un événement effectivement survenu en amont d'un autre événement passé pris comme repère.

Étape $\mathrm{n}^{\circ} 2$ : si le contexte offrait le moyen de construire cette représentation, la forme est alors entendue comme une forme virtualisante, qui montre un événement passé hypothétique, un entier de virtualité révolu et donc privé de toute réalisation possible (« irréel du passé »).

Étape $n^{\circ} 3$ : le révolu étant l'apanage des formes composées, des formes d'aspect transcendant, on en vient à associer cette valeur d'irréel du passé aux seules formes composées (hubiera querido) et la forme simple, immanente (quisiera) se voit chargée de porter la représentation d'un événement pensé comme hypothétique, de réalisation 
hautement improbable mais non encore totalement «jouée " (hypothèses a contrario « irréel du présent »).

La question qui se pose au traducteur, dès lors qu'il n'est pas le contemporain de Cervantès, est donc celle-ci : l'usage que fait Cervantès de la forme en -ra est-il celui, ultime, que nous connaissons aujourd'hui ou peut-il être compté au nombre des archaïsmes et de quelle sorte ? Cervantès écrit :

2) Desocupado lector, sin juramento me podrás creer que quisiera que este libro, como hijo del entendimiento, fuera el más hermoso, el más gallardo y más discreto que pudiera imaginarse. Pero no he podido yo contravenir á la orden de naturaleza; que en ella cada cosa engendra su semejante. Y así, ¿ qué podía engendrar el estéril y mal cultivado ingenio mío sino la historia de un hijo seco, avellanado, antojadizo, y lleno de pensamientos varios y nunca imaginados de otro alguno... ? [...] Sólo quisiera dártela monda y desnuda, sin el ornamento de prólogo, ni de la inumerabilidad y catálogo de los acostumbrados sonetos, epigramas y elogios que al principio de los libros suelen ponerse.

Porque te sé decir que, aunque me costó algún trabajo componerla, ninguno tuve por mayor que hacer esta prefación que vas leyendo.

(Ed. Clásicos Castellanos, t. I, p. 7 et p. 9-10).

Par deux fois l'expérience évoquée correspond au schéma "quisiera fablar e non lo pude fazer ». Très directement d'abord, avec l'aveu «Pero no he podido... ». La seconde fois, à travers l'évocation de l'effort excessif que lui impose ladite préface. L'échec ainsi confessé exerce un rôle rétroactif et n'en pas tenir compte affecterait la cohérence et pourrait sembler une maladresse. La situation invite à déclarer un souhait caduc, et cela conduit à estimer que l'emploi fait de quisiera correspond à l'étape $n^{\circ} 2$.

Pour qui postule qu'à même date, qui plus est sous la même plume, le signifiant quisiera ne saurait prendre diverses valeurs discursives, il faut alors faire l'hypothèse qu'en tout autre emploi le signifié sera celui-ci. À moins que Cervantès ne joue la carte de l'archaïsme volontaire. Ce qui ramènerait à l'étape $n^{\circ} 1$. Mais on se refusera, $a$ priori, à admettre que certains emplois correspondent à l'étape $\mathrm{n}^{\circ} 3:$ on la tiendra pour étrangère à l'usage de Cervantès ${ }^{21}$. Et l'on examinera tout autre emploi dans cette perspective. L'hypothèse, bien évidemment, devrait être abandonnée si certains emplois y perdaient toute intelligibilité.

3) Nunca fuera caballero

De damas tan bien servido

Como fuera don Quijote

Cuando de su aldea vino:

Doncellas curaban dél;

Princesas, del su rocino.

o Rocinante; que éste es el nombre, señoras mías, de mi caballo, y don Quijote de la Mancha el mío; que, puesto que no quisiera descubrirme fasta que las fazañas fechas en vuestro servicio y pro me descubrieran, la fuerza de acomodar al propósito presente este romance viejo de Lanzarote ha sido causa que sepáis mi nombre antes de toda sazón; pero tiempo vendrá en que las vuestras señorías me manden y yo obedezca, y el valor de mi brazo descubra el deseo que tengo de serviros. (Ibid., chap. II, p. 84-85)

De l'exemple $\mathrm{n}^{\circ} 3$ on a déjà commenté le début. Qu'il reflète l'étape $\mathrm{n}^{\circ} 1$ n'a rien de surprenant. Don Quichotte y pastiche, de son propre aveu, le «romance viejo de Lanzarote» et ces emplois relèvent des archaïsmes volontairement produits par 
Cervantès - emplois qui font l'objet de la suite du présent article. D'autres éléments linguistiques (fasta - fazañas - fechas - las vuestras senorías) le confirment, le discours de don Quichotte est troussé à l'ancienne et les formes en - ra qu'il contient relèvent soit de l'étape 1 (auquel cas elles rejoignent ces éléments archaïsants) soit de l'étape 2 (et s'ajoutent alors à tout ce qui appartient encore en propre à la langue de Cervantès) : c'est à la seconde solution, semble-t-il, que l'analyse mène et les traductions, en majorité, montrent que leurs auteurs souscrivaient à cette même analyse.

\begin{tabular}{|c|c|}
\hline \multicolumn{2}{|c|}{ Exemple 3 } \\
\hline a & je n'eusse voulu / m'eussent fait \\
\hline b & je voulais / vous apprissent \\
\hline c & je ne voulusse pas / m'eussent découvert \\
\hline d & j'eusse désiré / m'eussent révélé \\
\hline e & je n'avais l'intention / m'eût révélé \\
\hline f & je n'aie pas voulu/ ne me découvrent \\
\hline g & je n'eusse pas voulu/ ne me découvrent \\
\hline h & n'eusse voulu / me découvrissent \\
\hline i & je n'eusse voulu / m'eussent fait \\
\hline
\end{tabular}

4) - Todo el mundo se tenga, si todo el mundo no confiesa que no hay en el mundo todo doncella más hermosa que la Emperatriz de la Mancha, la sin par Dulcinea del Toboso.

Paráronse los mercaderes al son destas razones, y á ver la extraña figura del que las decía, y por la figura y por las razones luego echaron de ver la locura de su dueño; mas quisieron ver despacio en qué paraba aquella confesión que se les pedía, y uno de ellos, que era un poco burlón y muy mucho discreto, le dijo:

- Señor caballero, nosotros no conocemos quién sea esa buena señora que decís; mostrádnosla: que si ella fuere de tanta hermosura como significáis, de buena gana y sin apremio alguno confesaremos la verdad que por parte vuestra nos es pedida.

- Si os la mostrara - replicó don Quijote -, ¿qué hiciérades vosotros en confesar una verdad tan notoria? La importancia está en que sin verla lo habéis de creer, confesar, afirmar, jurar y defender; donde no, conmigo sois en batalla, gente descomunal y soberbia. Que, ahora vengáis uno á uno, como pide la orden de caballería, ahora todos juntos, como es costumbre y mala usanza de los de vuestra ralea, aquí os aguardo y espero, confiado en la razón que de mi parte tengo. - Señor caballero - replicó el mercader -, suplico á vuestra merced en nombre de todos estos príncipes que aquí estamos que, porque no encarguemos nuestras conciencias confesando una cosa por nosotros jamás vista ni oída, y más siendo tan en perjuicio de las emperatrices y reinas del Alcarria y Extremadura, que vuestra merced sea servido de mostrarnos algún retrato de esa señora, aunque sea tamaño como un grano de trigo; que por el hilo se sacará el ovillo, y quedaremos con esto satisfechos y seguros, y vuestra merced quedará contento y pagado; y aun creo que estamos ya tan de su parte, que, aunque su retrato nos muestre que es tuerta de un ojo y que del otro le mana bermellón y piedra azufre, con todo eso, por complacer á vuestra merced, diremos en su favor todo lo que quisiere. 
- No le mana, canalla infame -respondió don Quijote encendido en cólera-; no le mana, digo, eso que decís, sino ámbar y algalia entre algodones; y no es tuerta ni corcovada, sino más derecha que un huso de Guadarrama. Pero jvosotros pagaréis la grande blasfemia que habéis dicho contra tamaña beldad como es la de mi señora! (Clásicos Castellanos, t. I, chap. IV, p. 125-129.)

C'est en revanche d'une tout autre interprétation que relèvent les traductions proposées pour l'extrait ci-dessus. Les deux formes en -ra y sont prises pour des «irréels du présent ", analysées donc comme relevant de l'étape 3 de son évolution.

\begin{tabular}{|l|l|}
\hline \multicolumn{2}{|c|}{ Exemple 4 } \\
\hline a & Si je vous l'avais montrée, que feriez-vous \\
\hline b & si vous la voyiez, où serait \\
\hline c & Si je vous la faisais voir, où serait \\
\hline d & Si je vous la montrais, quel mérite auriez-vous \\
\hline e & Si je vous la montrais, quel mérite auriez-vous \\
\hline f & Si je vous la montrais, quel mérite auriez-vous \\
\hline g & Si je vous la montrais, que vous servirait \\
\hline h & Si je vous la montrais, que servirait \\
\hline i & Si je vous l'avais montrée, que feriez-vous \\
\hline
\end{tabular}

L'épisode narré y conserve une cohérence, une vraisemblance telles que chacun s'en est satisfait. Sommés de célébrer la beauté de Dulcinée, les marchands expriment le désir de voir auparavant son portrait. Leur répondant par un «Si je vous la montrais", don Quichotte se place alors dans une perspective d'acceptation de cette requête, une perspective hautement improbable certes, contraire à ses intentions, mais pour laquelle subsiste, puisqu'elle n'est pas caduque, une infime chance de réalisation.

Seule la traduction de Oudin, dans sa version originale (4 i) ou révisée par Cassou (4a), opte pour un "irréel du passé ", attribue à mostrara- mais non à hiciérades - la valeur qu'on a désignée comme celle de l'étape 2. Refusant a priori d'entrer en débat avec les marchands, dès lors qu'ils n'ont pas obtempéré - et sans doute obligé à cette intransigeance par l'impossibilité même où il se trouverait de produire le moindre portrait - don Quichotte répond par un irréel du passé, «si je vous l'avais montrée... ». L'affaire est jouée, il est trop tard, il fallait jurer sur le champ. Il n'est plus maintenant qu'une seule réponse, celle des armes.

Par rapport à l'autre lecture, celle-ci gagne en cohérence, s'accorde plus étroitement à la situation et au caractère du héros. Étendue à hiciérades, la traduction par des formes transcendantes du futur hypothétique permet de ne pas contrevenir à l'hypothèse qui situe à l'étape 2 le système linguistique de Cervantès. Que le contemporain de Cervantès retienne au moins en partie cette option constitue sans doute un bon indice de la justesse de notre hypothèse. Celle-ci trouve encore confirmation si l'on observe, chez Cervantès, les structures où se rencontre la forme en -se. Jamais, semble-t-il, cette dernière n'y entre 
en concurrence avec la forme en -ra; en particulier, toute construction dotée de prospectivité, comme, par exemple, une construction finale, exclut la forme en -ra..

\section{Les archaïsmes du parler de Don Quichotte}

Sans augmenter vraiment la difficulté, le parler de don Quichotte lui-même complexifie la tâche des traducteurs. Par une langue et une rhétorique tout ensemble désuètes, il crée pour le lecteur moderne - on l'a annoncé - une nouvelle distance, un fond plus éloigné encore que le reste de l'œuvre. Sans doute n'y recourt-il qu'épisodiquement, sans doute n'est-ce pas dans sa bouche la langue, en tout point exacte, du ou des siècles antérieurs. Cervantès n'en est pas à une reconstruction philologique scrupuleuse ; il n'en a que faire. Mais il donne à son personnage assez de mots, assez de formes, assez de tours pour que celui-ci, par place, ne se fasse pas comprendre ou soit un objet de risée ${ }^{22}$.

Il arrive que ce soit tout un discours qui, sur ce principe, soit tenu. C'est un peu de facilité ainsi qui se trouve offerte au traducteur : il n'est pas obligé strictement de distribuer les archaïsmes, d'une espèce ou d'une autre, aux mêmes points de la phrase. Tout un ensemble de compensations lui est permis : ce qu'il a perdu ici, il le rattrape là, et, s'il en est besoin, par un autre moyen. Une « vieillerie » morphologique impossible en français sera rachetée ailleurs par une « antiquaillerie » lexicale ou syntaxique. Ou inversement.

\section{La $2^{\mathrm{e}}$ personne du pluriel}

47 Maurice Molho écrivait, un jour, que don Quichotte " pasea una memoria errante que se ajusta a relojes cuya cadencia se rige según estrellas desaparecidas para $\operatorname{siempre}^{23}$. Eh bien, l'une de ces naines blanches et, pour nous, l'un de ces soleils définitivement éteints, paraît dans les exemples 4, 6 et 7 regroupés sous la lettre A.

A 4) - Señor caballero, nosotros no conocemos quién sea esa buena señora que decís; mostrádnosla: que si ella fuere de tanta hermosura como significáis, de buena gana y sin apremio alguno confesaremos la verdad que por parte vuestra nos es pedida.

- Si os la mostrara - replicó don Quijote -, ¿ qué hiciérades vosotros en confesar una verdad tan notoria ? La importancia está en que sin verla lo habéis de creer, confesar, afirmar, jurar y defender; donde no, conmigo sois en batalla, gente descomunal y soberbia. Que, ahora vengáis uno á uno, como pide la orden de caballería, ahora todos juntos, como es costumbre y mala usanza de los de vuestra ralea, aquí os aguardo y espero, confiado en la razón que de mi parte tengo. (Ibid., chap. IV, p. 125-129)

A 6) [...] - Bien parece la mesura en las fermosas, y es mucha sandez, además, la risa que de leve causa procede; pero non vos lo digo porque os acuitedes ni mostredes mal talante; que el mío non es de ál que de serviros.

El lenguaje, no entendido de las señoras...

(Ibid., chap. II, p. 79)

A 7) ¡Oh princesa Dulcinea, señora deste cautivo corazón! Mucho agravio me habedes fecho en despedirme y reprocharme con el riguroso afincamiento de mandarme no parecer ante la vuestra fermosura. Plégaos, señora, de membraros deste vuestro sujeto que tantas cuitas por vuestro amor padece.

(Ibid., chap. II, p. 72-73)

À la morphologie de $2^{\mathrm{e}}$ personne du pluriel ici en cause, comment trouver un équivalent en français? La morphologie verbale française sur ce point n'offre rien d'équivalent. Mais 
là n'est pas l'essentiel. Pour tout lecteur du Don Quijote, ces formes en -des sont toutes également archaïques. Il faudrait bien de l'attention - une attention qui ne peut être que celle du linguiste - pour observer qu'à certains temps les formes en-des alternent avec les formes modernes (ainsi, habedes en A 7 en face de habéis en A4) et que, pour d'autres temps, elles sont les seules à comparaître. En effet, l'histoire de ces formes, bien connue des linguistes, se déroule en deux temps. Jusqu'au $\mathrm{XV}^{\mathrm{e}}$ siècle la morphologie phonétiquement héritée du latin - TIS, est partout (sauf au prétérit) -des. À cette date commence à se produire comme une reprise de l'évolution qui, à travers l'amuissement $d u[\delta]$ intervocalique et la résorption de l'hiatus en diphtongue, aboutit aux formes actuelles. Mais seules les formes en -des paroxytoniques s'en voient affectées et, au bout d'un siècle, ce sont donc des formes oxytoniques en -is qui les ont remplacées. Sont concernés le présent et le futur de l'indicatif ainsi que le présent du subjonctif. Il faut en revanche attendre que le $\mathrm{XVII}^{\mathrm{e}}$ siècle soit bien entamé pour que les formes proparoxytoniques (que leur allure savante a peut-être protégées quand leur structure accentuelle aurait dû à l'inverse leur valoir une usure plus rapide) pour que ces formes donc - imparfait de l'indicatif, futur hypothétique, formes en -ra, -re et -se - emboîtent le pas aux formes paroxytoniques. Pour Cervantès donc hiciérades, cantásedes, tuviéredes, amábades ou pondríades sont les seules formes dont il a l'usage et elles viennent pour nous grossir les rangs des archaïsmes qui séparent le castillan de 1605 du castillan actuel. De telles formes se rencontrent donc dans la bouche de n'importe lequel des personnages, y compris dans celle de l'auteur ou de l'ami avec qui il converse dans le Prologue :

A n-Lo primero en que reparáis de los sonetos, epigramas ó elogios que os faltan para el principio, $y$ que sean de personajes graves y de título, se puede remediar en que vos mismo toméis algún trabajo en hacerlos, y después los podéis bautizar y poner el nombre que quisiéredes, ahijándolos al Preste Juan de las Indias ó al emperador de Trapisonda [...]

En lo de citar en las márgenes los libros y autores de donde sacáredes las sentencias y dichos que pusiéredes en vuestra historia, no hay más sino hacer de manera que vengan á pelo algunas sentencias o latines que vos sepáis de memoria [...]

(Ibid, Prólogo, p. 15-16)

Dans celle aussi de don Quichotte :

A 3) $O$ Rocinante; que éste es el nombre, señoras mías, de mi caballo, y don Quijote de la Mancha el mío; que, puesto que no quisiera descubrirme fasta que las fazañas fechas en vuestro servicio y pro me descubrieran, la fuerza de acomodar al propósito presente este romance viejo de Lanzarote ha sido causa que sepáis mi nombre antes de toda sazón; pero tiempo vendrá en que las vuestras señorías me manden y yo obedezca, y el valor de mi brazo descubra el deseo que tengo de serviros. (Clásicos Castellanos, t. I, chap. II, p. 84-85).

A 4) - Señor caballero, nosotros no conocemos quién sea esa buena señora que decís; mostrádnosla: que si ella fuere de tanta hermosura como significáis, de buena gana y sin apremio alguno confesaremos la verdad que por parte vuestra nos es pedida.

- Si os la mostrara - replicó don Quijote -, ¿ qué hiciérades vosotros en confesar una verdad tan notoria ? La importancia está en que sin verla lo habéis de creer, confesar, afirmar, jurar y defender; donde no, conmigo sois en batalla, gente descomunal y soberbia. Que, ahora vengáis uno á uno, como pide la orden de caballería, ahora todos juntos, como es costumbre y mala usanza de los de vuestra ralea, aquí os aguardo y espero, confiado en la razón que de mi parte tengo. - Señor caballero - replicó el mercader -, suplico á vuestra merced en nombre de todos estos príncipes que aquí estamos que, porque no encarguemos nuestras conciencias confesando una cosa por nosotros jamás vista ni oída, y más siendo tan en perjuicio de las emperatrices y reinas del Alcarria y Extremadura, que vuestra merced sea servido de mostrarnos algún retrato de esa señora, 
aunque sea tamaño como un grano de trigo; que por el hilo se sacará el ovillo, y quedaremos con esto satisfechos y seguros, $y$ vuestra merced quedará contento y pagado; $y$ aun creo que estamos ya tan de su parte, que, aunque su retrato nos muestre que es tuerta de un ojo y que del otro le mana bermellón y piedra azufre, con todo eso, por complacer á vuestra merced, diremos en su favor todo lo que quisiere.

- No le mana, canalla infame - respondió don Quijote encendido en cólera -; no le mana, digo, eso que decís, sino ámbar y algalia entre algodones; y no es tuerta ni corcovada, sino más derecha que un huso de Guadarrama. Pero ; vosotros pagaréis la grande blasfemia que habéis dicho contra tamaña beldad como es la de mi señora!

(Ibid., chap. IV, p. 125-129)

49 Ces formes, comme on le voit, coexistent avec les formes modernes tout au long de ce même prologue et de toute l'œuvre, dans la bouche de don Quichotte aussi bien que dans celle des autres personnages. Mais seul don Quichotte use des formes paroxytoniques (ex. A 7 : habedes). Les contemporains de Cervantès y reconnaissaient des formes tout droit venues des romans de chevalerie. Oudin était du nombre et n'a pas manqué de s'interroger. C'était un détail qui s'ajoutait à d'autres. Les traducteurs auraient pu jouer sur une graphie, écrire fayct en place de fait, dans le dernier exemple. Le lecteur français aurait identifié un archaïsme. Mais il lui aurait fallu un savoir philologique certain pour mettre cet archaïsme au compte de la langue en usage en 1605 ou l'imputer au désir d'imiter la parlure médiévale.

\section{Yantar}

Plus ardus sont les cas où le décalage linguistique ne trouve à se marquer que dans un seul vocable. Et davantage encore quand celui-ci porte sur une réalité des plus ordinaires, des plus quotidiennes.

51 " Se restaurer ", «manger » est de cette espèce. Dans la première auberge où il lui est donné de s'arrêter, aux mozas qu'il vient d'apostropher, qui n'entendent rien à son discours ${ }^{24}$ et lui demandent si quería comer alguna cosa, don Quichotte répond :

(3) Cualquiera yantaría yo [...], porque, a lo que entiendo, me haría mucho al caso.

Deux façons de faire référence au même acte : comer, yantar. Mais du second, déjà en 1535 ou 1536, J. de Valdés dans son Diálogo de la lengua écrit : « Entre gente vulgar dizen yantar, en corte se dize comer ; un refrán no malo usa yantar, diziendo : El abad de donde canta, de allí yanta. $\aleph^{25}$ Vulgaire sans doute, mais vulgaire parce qu'ancien et que seuls les rústicos en avaient conservé l'usage. Le vrai est que dans les siècles antérieurs yantar était la façon naturelle de dire. Et c'est à ce titre qu'il paraît dans le proverbe et dans la bouche de don Quichotte. Les Autoridades, un grand siècle plus tard, donnent encore assez bien l'effet que pareil mot pouvait produire en 1605 ( «Es voz antigua») et ne trouvent à citer que notre exemple de Cervantès. Bref, ce qui, pour le traducteur, est à retenir, J. Corominas ${ }^{26}$ le résume clairement : "... sólo con el carácter de palabra villanesca o anticuada llega hasta escritores del Siglo de Oro, como Cervantes o Quevedo ».

Les traducteurs sont loin de s'en être avisés, ou d'avoir cherché à en tenir compte. Un premier $(5$ b), comme à son habitude, escamote la difficulté (Il répondit franchement qu'il avait besoin de dîner).

Un second ( $5 c$ ), par la conjonction d'un passé du subjonctif (quoi que ce fût), d'un verbe ( s'accommoder), qui sans doute - exquise politesse - évite de nommer les vulgaires 
fonctions du corps (manger), et, enfin, par fort à point, juge en avoir assez fait pour jeter son personnage dans le ridicule, pour le mettre hors du temps. Pour marquer, à vrai dire, son extravagance. Mais, outre que par le verbe s'accommoder et par quoi que c'est traduire deux fois ${ }^{27}$ cualquiera, il faut bien reconnaître que ce sont là autant de formes linguistiques qui ont cours dans tout l'ouvrage. Qu'elles sont dans la bouche des autres personnages comme dans les parties narratives. Évanouie donc la singularité surannée de don Quichotte.

Un troisième $(5 d)$ s'en tient au ton le plus neutre, ni exagérément moderne ou familier, ni, comme il faudrait, marqué par le temps. Car si prendre ou manger un morceau est, avec les ans, devenu " populaire », il n'était au XVII e siècle que « familier ». Littré rappelle que morceau, pris pour " portion séparée d'une chose solide, bonne à manger ", a là son « sens premier, puisque, étymologiquement, un morceau est une chose mordue, une bouchée ${ }^{28}$. Reste que le futur (prendrai) a quelque chose de bien catégorique et peut-être de mal venu dans un de ces moments où don Quichotte s'exerce à une courtoisie délicate et hors de mode.

565 e propose, lui, une façon de dire qui aurait sa place dans une gargote d'aujourd'hui, urbaine ou rurale. Réponse expéditive : elle se réduit à donner un complément (N'importe quoi) au verbe de la question et à reprendre ce complément sous la forme la plus vague et la plus familière (ça) : N'importe quoi, répondit don Quichotte, et je crois que ça tomberait bien. 5 $g$ n'en use pas autrement, si ce n'est que le commentaire travaille à rattraper la brutalité de la réponse : à ce que j'entends a plus de tenue, et ici peut-être plus d'âge, que je crois; et venir à point, d'autre part, plus de distinction que tomberait bien.

Autre manœuvre, celle de $5 f$ qui étire le propos et semble attendre des blanches mains et de fort à point (déjà présent dans $5 c$ ) une patine qui ferait rire. Il est à craindre qu'il n'y ait que les mozas pour s'étonner de la mauvaise vue de leur hôte : il prend le brun pour de l'albâtre.

Il n'est que $5 a$ et $5 \mathrm{~h}$ pour avoir cherché à donner de yantar une traduction directe. L'un et l'autre recourent à sustenter. Chez le premier, on relèvera que c'est la seule correction apportée au texte de $\mathrm{C}$. Oudin, mais on relèvera aussi que les deux mettent le verbe au pronominal, ce qui est peut-être un anachronisme ${ }^{29}$. À quoi ils répondraient sans doute qu'il n'est pour s'en blesser que quelques philologues grincheux, et que l'important ici était de parler hors du naturel attendu. Soit. De toute façon, leur répliquera-t-on, on y parvenait un peu plus - et très aisément - en adoptant la graphie ancienne : substanter. Et, dans le cas de $5 h$, en évitant un ça, bien sûr inconnu de Furetière et que Littré encore ne trouve à illustrer que par un exemple de... Béranger.

L'affaire, il faut l'avouer, avait sa difficulté. Mais qui pensera que le français est totalement sans ressources et, en 1614, tout à fait impuissant à dire, de façon désuète et extravagante, qu'on "ne fera pas le difficile ", que tout est bon de ce qu'on servira ? Un premier moyen, quel que soit le verbe retenu, est de faire l'économie du pronom sujet, personnel ou impersonnel ${ }^{30}$. Dans la quête de ce verbe il peut, d'autre part, être de bonne méthode de se souvenir de l'histoire de yantar. Issu de jajantare, forme vulgaire de jajentare, il signifiera d'abord, conformément à l'étymologie, "rompre le jeûne ", puis désignera le repas de midi et, «sobre todo en fecha tardía, yantar se hace sinónimo de comer en general y a cualquier hora $»^{31}$. Évolution voisine donc du français desjeuner, même si la spécialisation du mot s'est peut-être faite dans un ordre différent : c'est assez pour accepter de s'en servir, et au pronominal comme on le voit faire, par exemple, aux 
$\mathrm{XIV}^{\mathrm{e}}, \mathrm{XV}^{\mathrm{e}}$ et même XVI ${ }^{\mathrm{e}}$ siècles, chez Froissart, chez Rabelais, chez Montaigne et bien d'autres ${ }^{32}$. Que, dès lors, l'on fasse dire à don Quichotte :

5 j) Quelle chose que soit bien voulentiers m'en desjeuneroys, car, à ce que m'en semble, elle me viendroit moult à propos.

ou :

- De toute chose bien voulentiers me desjeuneroys...

bien voulentiers servant ici, sans qu'il soit nécessaire, à marquer, dans l'original, la présence de yo. De façon plus lâche, plus libre aussi, comme tant d'autres ne traduisant pas vraiment yantar, il était possible de se satisfaire de :

- De quelque chere [ou quelque viande] que soit me contenteroys...

D'autres solutions, bien sûr, pourraient être proposées, qui, comme celles-ci, feraient au lecteur français d'aujourd'hui l'honneur d'être traité comme Cervantès traite, aujourd'hui, son lecteur espagnol. Elles lui imposeraient au moins de soupçonner deux usages de la langue que l'histoire distingue - et même trois, avec le sien propre. Elles lui feraient apercevoir que c'est une ressource dont ne se prive pas le Don Quichotte. Une ressource même sur laquelle il se fonde.

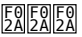

61 Derniers exemples qu'on examinera, et qui auraient dû donner moins de tablature aux traducteurs: la première apostrophe de don Quichotte aux mozas de l'auberge, la première invocation à Dulcinée et la lettre à la même Dulcinée.

(6) Non fuyan las vuestras mercedes, ni teman desaguisado alguno; ca á la orden de caballería que profeso non toca ni atañe facerle á ninguno, cuanto más á tan altas doncellas como vuestras presencias demuestran.

[...] Bien parece la mesura en las fermosas, y es mucha sandez, además, la risa que de leve causa procede; pero non vos lo digo porque os acuitedes ni mostredes mal talante; que el mío non es de ál que de serviros.

El lenguaje, no entendido de las señoras...

Ed. Clásicos Castellanos, t. I, chap. II, p. 79.

(7) ¡Oh princesa Dulcinea, señora deste cautivo corazón! Mucho agravio me habedes fecho en despedirme y reprocharme con el riguroso afincamiento de mandarme no parecer ante la vuestra fermosura. Plégaos, señora, de membraros deste vuestro sujeto corazón, que tantas cuitas por vuestro amor padece.

Ibid., p. 72-73.

(8) Soberana y alta señora:

El ferido de punta de ausencia y el llagado de las telas del corazón, dulcísima Dulcinea del Toboso, te envía la salud que él no tiene. Si tu femosura me desprecia, si tu valor no es en mi pro, si tus desdenes son en mi afincamiento, maguer que yo sea asaz de sufrido, mal podré sostenerme en esta cuita, que, además de ser fuerte, es muy duradera. [...] Si gustares de acorrerme, tuyo soy; y si no, haz lo que te viniere en gusto; que con acabar mi vida habré satisfecho á tu crueldad y á mi deseo. Tuyo hasta la muerte.

Ibid., t. II, chap. XXV, p. 313-314.

Ces exemples, parmi quelques autres, et plus les derniers que le premier, ont mérité l'attention des annotateurs. Tout a été dit de ce qui était possible sur l'origine de ces propos : rhétorique de la poésie courtoise, topiques des déclarations amoureuses dans les romans de chevalerie, thèmes de «la Belle dame sans mercy », etc. On a parfois pu 
deviner - ou supposer - les œuvres dans lesquelles serait allé puiser Cervantès. Mais rien, ou presque, de la citation littérale n'a été trouvé : le souvenir plutôt d'une idée et de quelques tours, quelques mots qui servaient à son expression. Le traducteur peut s'en autoriser pour ne pas se croire tenu à une étroite littéralité sémantique. Mais ce qu'il ne faut pas manquer de voir, c'est la façon de faire de Cervantès : il distribue, de place en place, des marques sorties de l'usage, ou que l'on est en train de délaisser. Il en met assez pour suggérer le parler d'un autre âge et plus qu'il ne serait nécessaire pour appeler le rire :

63 1) Il multiplie les vocables qui portent un $f$ (initial ou pas) là où il faudrait, pour son lecteur, un $h$ : fuyan, facerle, fermosas (ex. 6), fecho, afincamiento, fermosura (ex. 7), ferido, fermosura, afincamiento (ex. 8).

2) Il recourt à des traits morphologiques depuis des lustres abandonnés :

a) pour la négation : non (ex. $6: 4$ fois), mais no (ex. 7 et $8: 2$ fois) et jamais nin en lieu et place de ni.

b) dans le domaine pronominal: vos (ex. 6) en position de complément non prépositionnel.

c) pour les conjonctions ou mots de liaison : ca (ex. 6), maguer (ex. 8).

d) dans le domaine verbal : acuitedes, mostredes (ex. 6), habedes (ex. 7) dont les désinences ont été étudiées plus haut.

3) Il joue, sans rigueur philologique, de la double syntaxe ${ }^{33}$ du possessif (articulé ou non) :

a) las vuestras mercedes (ex. 6), la vuestra fermosura, este vuestro sujeto (ex. 7).

b) vuestras presencias (ex. 6), vuestro amor (ex. 7), tu fermosura, tu valor, tus desdenes, tu crueldad, mi deseo (ex. 8).

4) Il use de tours qui, sans être tous complètement sortis de l'usage, et qui n'ont donc pas tous même date, sont en voie de disparition : mal talante, non es de ál que (ex. 6), asaz de, en mi pro (ex. 8).

5) Il lâche, ici ou là, quelques éléments lexicaux qui, dans le parler vif, ont depuis longtemps trouvé des remplaçants : desaguisado (ex. 6), afincamiento (ex. 7 et 8), cuitas (ex. 7 et 8), membraros (ex. 7), acorrer (ex. 8).

64 Il est aisé de voir ce qui de tout cela se conserve ou s'évanouit après le passage des traducteurs. L'erreur, ou la folie, serait de vouloir, aux mêmes places, mettre en français ce qui pour un public du XVII ${ }^{e}$ siècle était des façons de dire ou dépassées ou déjà incompréhensibles. Ce serait le croire possible et prétendre traduire une langue quand il n'y a de traduction que des discours. Mais rien ne s'oppose à ce qu'à un discours espagnol on substitue un discours français de même époque. La littérature française, prose et poésie, abonde bien évidemment en notions et en figures, en idées qui sont celles-là mêmes que porte le parler de don Quichotte. Il n'est besoin donc que de les y pêcher. Et qu'importe si l'ordre des mots n'y est pas strictement le même puisque ce qui est à dire et à montrer est un jeu de rapports : de la vie et de la mort, de la souffrance et du bonheur, de la liberté et des chaînes, de la cruauté et de la générosité, de l'amour et du dédain, du dévouement et de l'indifférence, de la mémoire et de l'oubli, de l'absence et de la présence, et, sur tout cela, d'un état de langue ancien et d'un autre plus ancien encore.

Certes, si l'on tient à ne pas s'écarter excessivement des cinq types d'archaïsmes énumérés ci-dessus, ce sera d'une bonne aide de se souvenir de quelques particularités du français des $\mathrm{XV}^{\mathrm{e}}$ et $\mathrm{XVI}^{\mathrm{e}}$ siècles entre autres. À la nature grapho-phonique du $f$ maintes fois répété, on répondra par la façon d'orthographier quelques éléments courants : poinct, ung, hault, fault, soubz, estre, gouster, vostre, etc. Par ce dernier (vostre) on aura au moins 
touché aussi la catégorie des possessifs, faute de pouvoir le faire par moyen de syntaxe. Dans le champ de la négation, poinct, mie et ne mis en place de ni sont des possibilités usuelles. Dans le domaine pronominal, comme signalé plus haut, on recourra à l'absence, possible dans des conditions précises, du pronom sujet et on aura souci de la place du pronom complément : pour le pouvoir dire. Par la désinence d'imparfait (-oit, -oient) et quelques formes « irrégulières » de passé simple (prins, eustes, feist, meist) ou de participe ( prins), on aura, pour la morphologie verbale, un instrument peut-être utile. On trouvera pour l'expression de la cause, dans certaines conditions, pour ce que ou veu que $e^{34}$, pour celle de la concession combien $q u e^{35}$, ce nonobstant que ${ }^{36}$ et, respectivement, pour des tours comme mal talante et non es de ál que, maltalent ${ }^{37}$ et fors que ${ }^{38}$.

\section{L'invocation à Dulcinée}

66 Ce que pourrait dès lors être l'invocation à Dulcinée, il est aisé de le deviner. Quelques lectures de plus, dans des pages correspondantes de la littérature française, et on pourrait avoir, par exemple :

6 j) Ô princesse Dulcinée, maistresse [souveraine] de mon cueur chetif [prisonnier], fort grand oultrage [dommaige] m'avez faict lors même que m'avez debouté [banni, rebouté] et remonstré, vous qui avecques tant grand rigueur m'avez par devers vostre beaulté requis [enjoinct] de ne point paroistre. Plaise à vous, ma Dame, de vous remembrer celuy qui sa vie a en vostre mercy close et tout meurdry de vostre Amour se treuve.

Rien là, bien sûr, qui ne soit du copiage. Mais Cervantès lui-même avait-il opéré d'une autre façon ? Les souvenirs qu'il mobilisait auraient pu être autres, comme à « vous qui avecques tant grand rigueur m'avez par devers ${ }^{39}$... » aurait pu être préféré : «... fait reproche avecques ferme commandement de poinct par devers vostre b.... » Ce ne serait que changer de modèle : comme dire, plus droitement, "de vous recorder ${ }^{40}$ ce subject vostre ", au lieu du long et déployé " qui sa vie a en vostre mercy close $»^{41}$, serait abandonner A. Chartier et le rappeler, en fin de phrase, écartant Marot ${ }^{42}$, pour déclarer à son exemple « qui mal ardant et chault souffre pour vous bien vouloir $\aleph^{43}$. Comme de choisir, enfin, debouter ou rebouter pour traduire despedirme serait, dans La Belle dame sans mercy, se souvenir de l'Amant ${ }^{44}$.

Il est aisé de le constater : un seul traducteur $(7 \mathrm{~h})$ a refusé le pronom sujet (grand dommage m'avez fait), moyen nécessaire et facile de donner " un coup de vieux " aux phrases de don Quichotte. Les autres, ou bien n'ont eu souci d'aucune patine ( $7 b$ et $7 e$ ) ou bien ont semé, ici et là, quelques "archaïsmes", mais dès lors dans des structures « modernes » où ils jurent, et parfois de façon criante :

- on supprime l'article ( $7 \mathrm{a}$ : fait grand grief ; $7 \mathrm{f}$ : c'est grande offense).

- on antépose un syntagme, généralement complément $\left(7 \mathrm{a}:\right.$ qui tant de misères endure ${ }^{45}$ ; $7 \mathrm{c}$ : une grande injure vous m'avez faite ; $7 \mathrm{f}$ : par vous asservi ; pour l'amour de vous souffrant mille peines).

- au verbe simple (se souvenir) on substitue une locution : avoir souvenance ( 7 c et $7 \mathrm{~g}$ ).

69 C'est peu. La statistique, certes, n'a pas à être la règle ultime du jugement, mais on peut estimer que c'est trop peu. Il n'est que $7 \mathrm{~h}$ pour avoir continûment eu la volonté de donner à un discours-pastiche une vraisemblance suffisante. Les antépositions nécessaires s'y trouvent ; le verbe (cf. pâtit) est, lorsqu'il convient, rejeté, à la latine, en fin de phrase ; en est évité devant le gérondif. Et tout anachronisme, à la réserve d'incriminer ${ }^{46}$, est banni du lexique : les " mots disparus » (ramentevoir) sont mêlés à ceux qui ont eu assez de vie pour venir - au moins sous leurs dehors - jusqu'à nous (maîtresse, prisonnier, serf, 
maux). Mais c'est encore trop faire sans doute pour «ceux qui ont cherché à accorder Cervantès aux façons de penser et de sentir de leurs contemporains", pour ceux qui aspirent à une version « forgée dans le creuset d'un français vivant, celui que nous lisons, écrivons et parlons et, comme telle, conforme à nos mœurs comme à l'attente de nos contemporains", pour ceux qui, au moindre mot ancien, croient voir des œuvres « encombrées d'archaïsmes, alourdies de tournures périmées et souvent opaques », des œuvres qui « déconcertent le lecteur d'aujourd'hui », bref, pour ceux qui leur trouvent "le défaut d'être écrites en un français archaïque et parfois barbare». Ils encensent Molière mais s'étoufferaient devant un don Quichotte qui se dirait meurtri de l'amour où « il se treuve ». Peut-être leur faudrait-il taxer aussi Molière d'opaque et de barbare; car, dans la bouche d'Alceste, il a fait rimer veuve et treuve ${ }^{47}$. Mais c'est qu'on regarde, explicitement, aux conséquences (les lecteurs) et détourne les yeux, délibérément ou pas, de la cause (l'œuvre à traduire).

\section{La lettre à Dulcinée}

Rien de bien autre dans la lettre de don Quichotte. Et, sans entrer dans le détail de l'affaire, on peut, dans des circonstances à peine différentes, retrouver chez les traducteurs les traits que l'on vient d'examiner.

71 La première phrase est sans doute le comble de l'artifice et de la contorsion. Ils tiennent à ce que son auteur se désigne lui-même, substantivement, sous l'espèce de l'objet qu'un procès a frappé : il est le siège de ferir et de llagar. Or, rien de moins naturel que d'appréhender un phénomène de cette façon. Le mouvement le plus spontané, en effet, est de prendre son départ à l'agent et non au patient ${ }^{48}$. Cette extravagance retenue par Cervantès, quatre traducteurs ( $8 \mathrm{a}, 8 \mathrm{c}, 8 \mathrm{~h}$ et $8 \mathrm{i}$ ) la conservent et ouvrent la lettre par l'article. Les cinq autres séparent les procès et l'être qu'ils affectent. Ce dernier s'en trouve "substantifié » sous l'espèce d'un «pronom démonstratif» (celui) et, par conséquence, paraît avant ce dont il pâtit. Trois fois $(8 b, 8 e, 8 f)$, comme l'était l'article, celui est répété, ce qui, sous une autre forme, maintient l'effet de surenchère que Cervantès obtenait par la reprise des participes substantivés (el ferido [...] el llagado). Deux fois $(8 d, 8 g)$, la répétition est refusée, les deux participes (frappé / blessé - féru / déchiré) sont contraints de s'articuler sur le même auxiliaire : le second syntagme s'absorbe dans le premier et l'impression d'emphase, de diction ampoulée, en est amortie.

Comme on pouvait le deviner, l'acceptation de l'article permet de ne pas détruire le parallélisme que présente l'original $(8 a, 8 c, 8 i)$. Cassou $(8 a)$, sans rien briser de l'équilibre des deux membres de la phrase, se contente de corriger les toiles du cour qui, chez Oudin( 8 i), lui auront paru trop étranges ${ }^{49}$. Souvenir peut-être, dans Le Cid, des "stances de Rodrigue $\aleph^{50}$, il leur préfère le fond du cœur. $8 \mathrm{~h}$, par l'introduction d'une relative (le n. que point l'a.), attente - mais très modérément - au parallélisme syntaxique, mais l'archaïsme $\mathrm{du}$ verbe choisi (poindre) est une compensation parfaite. Avec celui, les relatives deviennent une obligation. Et l'on aura $(8 a, 8 e, 8 f)$ ceux qui se permettent une variation ( celui qui / que [...] celui dont) et ceux qui, pour l'effet indiqué plus haut, appuieront tout le discours sur un seul relatif qui $(8 \mathrm{~d}, 8 \mathrm{~g})$.

Sans doute le côté chargé et outré de la lettre se conserve-t-il plus aisément par le choix du maintien des articles. C'est aussi bien celui qu'ont fait, on l'a vu, le traducteur le plus ancien, son réviseur et, plus tard, celui $(8 \mathrm{~h})$ dont le parti, le plus clairement, a été de laisser à l'œuvre tout son âge. Mais on y parvenait tout pareillement avec le démonstratif, 
pour autant qu'on accepte, ensuite, de puiser dans le lexique de la littérature ancienne et de même genre. Le français, à côté de blesser, avait bien sûr férir ${ }^{51}$ mais aussi navrer ${ }^{52}$; et llaga (< plaga) pouvait faire souvenir de plaie / player $^{53}$. De l'idée de punta il était loisible de tirer pointe $e^{54}$ (ainsi du reste ont fait $8 a, 8 c, 8 \mathrm{~d}, 8 \mathrm{~g}, 8 \mathrm{i}$ ), mais aussi le verbe poindre ${ }^{55}$ (voir $8 \mathrm{~h}$ ) et même le substantif poincture ${ }^{56}$, ou dard ${ }^{57}$, si fréquents dans la poésie amoureuse. Dernière possibilité enfin, sans déserter le champ de la lance et de la pointe qui blesse, picquer dru ${ }^{58}$.

On voit par là ce qu'en français aurait pu être, à son ouverture, la lettre de don Quichotte :

$8 \mathrm{j})$ Le navré [Le feru] de la poincture de l'absence \& le playé jusques au fond du cueur, trop plus que doulce Dulcinée du Toboso, te mande l'heur qui tollu ${ }^{59}$ luy a été [te souhaite la santé que n'a poinct].

$\mathrm{Ou}$ :

- Celluy que poingt l'absence \& celluy qui au tresfonds du cueur est navré [playé] ...

- Celluy que picque dru l'absence \& celluy qu'Amour au tresfonds de son cueur a mordu...

- Qui du dard de l'absence est feru [navré] \& au tresfonds de son cueur playé...

Et si l'on voulait poursuivre de la même encre on essayait, traduisant desprecia par déprime ${ }^{60}$ ou desprise ${ }^{61}$, de rattraper l'insatisfaction laissée par la difficulté qu'il y a à rendre justement afincamiento : Si ta beaulté me deprime... Comme on prenait soin de ne pas donner à la concession (maguer que) une forme trop moderne (seul en a eu souci $8 e$ qui recourt au malgré que des Classiques, plus tard condamné par les puristes), et, suivant la syntaxe de l'original, de conserver (comme font $8 c$ et $8 \mathrm{~h}$ ) l'antéposition de mal. Sans oublier, enfin, que asaz de est en 1605, et depuis plusieurs lustres, une façon désuète de dire la quantité6 ${ }^{62}$, que l'archaïsme donc est manqué par ceux qui se contenteront d'un assez patient. $8 \mathrm{~h}$ se rattrape par la postposition de assez, mais on peut juger qu'on disposait d'autres moyens : plus assez que $e^{63}$, trop plus que ${ }^{64}$, etc. ; qu'il y eut, enfin, un moment de l'histoire du français où "souffrance était synonyme de patience et aussi de tolérance " ${ }^{65}$; que souffrant ${ }^{66}$ donc signifiait " patient, endurant » : "Ne dites rien à ce fanfaron, car il n'est point du tout souffrant " écrivait encore Furetière dans son Dict. universel. Et on en venait ainsi à traduire par exemple :

$8 \mathrm{j})$...combien que plus assez je sois souffrant, mal me pourray soustenir en ce dueil ${ }^{67}$ [ce tourment] qui, oultre que fort, me dure [est durable].

Pour le reste, en prenant soin, à l'exemple du seul $8 h$, d'éviter ${ }^{68}$ la préposition de pour introduire l'infinitif secourir, rien de plus simple à trouver, dans la littérature d'époque, que l'équivalent presque strict de cette rhétorique amoureuse :

$8 \mathrm{j}$ ) S'il vous [te] plaist me donner secours ${ }^{69}$ [Si vous agrée me secourir], je suis vostre et vostre me tiens $^{70}$; et sy non, faictes ce qui en vostre gré sera.

\section{La première apostrophe de don Quichotte}

Son examen sans doute ne montrerait rien de plus. Rien, si ce n'est que les traductions proposées - hormis $6 \mathrm{~h}$ qui multiplie les archaïsmes de toute espèce - s'accommodent plutôt mal du commentaire qui doit les suivre : «El lenguaje, no entendido de las señoras... » 6 $b$ et $6 e$, qui parlent, le premier d'un « langage fort étranger aux jeunes filles", le second d'un "langage nouveau pour ces dames", ont choisi, à dessein ou pas, de laisser comprendre qu'il y avait là pour elles une façon de dire inaccoutumée, inédite, mais sans déclarer explicitement qu'elles n'y entendaient goutte. $6 \mathrm{~b}$ et $6 e$ sont aussi bien ceux qui, en l'occurrence, se gardent de tout archaïsme. Don Quichotte, sous leur plume, parle la 
langue la plus lisse, la plus droite, la plus « contemporaine » qui soit. Ce qui échappe aux " hautes damoiselles » ne peut donc être que le contenu du propos, son "étrangeté », sa «nouveauté ». Nullement les termes où il est tenu. La cohérence, par suite, y est, si l'exactitude est oubliée. Mais les deux s'évanouissent si les paroles de don Quichotte se laissent entendre et, l'instant d'après, sont dites indéchiffrables.

Ici encore, moyennant le souvenir de quelques lectures - ce qui n'est que prendre le pli de don Quichotte lui-même -, on semait les deux phrases de quelques tournures, par leur âge inintelligibles au commun des autres personnages, et l'affaire était... entendue. L'on pouvait même se payer le luxe de respecter un trait de langue bien répandu aux $\mathrm{XVI}^{\mathrm{e}}$ et XVII e siècles : les « sinónimos voluntarios »"1 , les "parejas de sinónimos». Si l'on manquait à le faire où il paraît (non toca ni atañe) $)^{72}$, par compensation on le plaçait ailleurs, là où il était absent. Par exemple, pour dire el mío [mi talante] non es ál, on copiait sans vergogne A. Chartier ${ }^{73}$ et lançait : «Je n'ay desir ne autre affaire... » Et si on jugeait en avoir assez fait en doublant n'est escheu ${ }^{74}$ de devolu, comme atañe doublait non toca, on se contentait ici du seul je n'ay desir, ou de je ne chalenge rien ${ }^{75}$, que, heureux d'avoir sous la main cette fois un terme qui, s'ouvrant aujourd'hui sur un $h^{-}$, s'ouvrait autrefois sur un $f_{-}$, on faisait suivre, comme indiqué plus haut (cf. note 34), de fors que de :

$6 \mathrm{j}$ )...et crainte n'ayez qu'on vous offense; car à l'ordre de chevalerie que je professe n'est escheu ni devolu de le fayre aulcunement [...] ; mais ce ne vous dy pour vostre tourment ni pour qu'ayez mauvais talent; car n'ay desir ni aultre affaire fors que de vous servir [fors que mon service vous plaise].

Peut-on espérer qu'à parler ainsi, en français, don Quichotte ait chance de rendre vraisemblable ce qui, dans la suite immédiate, sera à traduire?

El lenguaje, no entendido de las señoras, y el mal talle de nuestro caballero acrecentaba en ellas la risa, y en él el enojo, y pasara muy adelante si á aquel punto no saliera el ventero, hombre que, por ser muy gordo, era muy pacífico ${ }^{76}$.

Plus vraisemblable du moins que si, pour rendre son non es ál que de, on lui fait dire, de façon toute neutre, n'est autre que, précédé ou suivi de mon intention $(6 a, 6 e, 6 f, 6 i)$, d'un autre substantif, humeur $(6 c, 6 \mathrm{~g})$, disposition(s) $(6 \mathrm{~d}, 6 \mathrm{~h})$, ou d'un simple verbe encadré de ne... que (6b).

\section{Conclusion}

81 Tout ce que des difficultés rencontrées par les traducteurs devant un texte du passé l'on vient de voir tient au souci, constant chez les uns, moins persistant chez d'autres mais jamais aboli, du lecteur qu'ils visent. Par choix délibéré maintes fois, sous la pression toujours des éditeurs et de l'opinion reçue, ils entendent lui faciliter la tâche. Ils veulent lui parler en "langue claire ». En une situation différente, ils ont en somme et à certains égards la philosophie du colonel Godchot qui, en 1933, publiait dans L'Effort Clartéiste ${ }^{77}$ un « Essai de traduction en vers français du Cimetière marin de Paul Valéry ». 


\section{ANNEXES}

\section{Le nom du héros}

1) Quieren decir que tenía el sobrenombre de Quijada, ó Quesada, que en eso hay alguna diferencia en los autores que deste caso escriben; aunque por conjeturas verosímiles se deja entender que se llamaba Quijana. Pero esto importa poco á nuestro cuento: basta que en la narración dél no se salga un punto de la verdad.

Cervantes, Don Quijote, ed. Clásicos Castellanos, t. I, p. 52-53.

[...] y en este pensamiento duró otros ocho días, y al cabo se vino a llamar don Quijote; de donde, como queda dicho, tomaron ocasión los autores desta tan verdadera historia que, sin duda, se debía de llamar Quijada, y no Quesada, como otros qusieron decir.

Ibid., p. 62.

1 a) On veut dire qu'il avait le surnom de Quixada ou Quesada (car en ceci il y a quelque différend entre les auteurs), encore que par conjectures vraisemblables on pense qu'il s'appelait Quixana ; mais cela importe peu à notre conte : il suffit qu'en la narration d'icelui on ne sorte un seul point de la vérité.

Trad. de César Oudin, revue par Jean Cassou, Paris, Gallimard, Folio classique, p. 68.

[...] et en cette pensée il passa huit autres jours, et enfin se vint à appeler don Quichotte ; d'où, comme dit est, les auteurs de cette tant véritable histoire ont pris sujet de dire que sans doute il se devait appeler Quixade, et non pas Quesada, comme d'autres l'ont voulu assurer.

Ibid., p. 71.

1 b) L'on prétend qu'il avait le surnom de Quixada ou Quésada. Les auteurs varient sur ce point. Ce qui parait le plus vraisemblable, c'est qu'il s'appelait Quixada. Peu importe, pourvu que nous soyons certains des faits.

Le Don Quichotte de la jeunesse, trad. de Michel de Cervantes par Florian, Paris, s.d., p. 4.

[...] et cela lui coûta huit autres jours. Enfin il se nomma don Quichotte. Mais se rappelant qu'Amadis...

Ibid., p. 6.

1 c) On a dit qu'il avait le surnom de Quixada ou Quesada, car il y a sur ce point quelque divergence entre les auteurs qui en ont écrit, bien que les conjectures les plus vraisemblables fassent entendre qu'il s'appelait Quijana. Mais cela importe peu à notre histoire ; il suffit que, dans le récit des faits, on ne s'écarte pas d'un atome de la vérité. Trad. Louis Viardot, Paris, éd. Bordas, « Les grands maîtres », 1949, p. 7.

[...] et cette pensée lui prit huit autres jours, au bout desquels il décida de s'appeler don Quichotte. C'est de là, comme on l'a dit, que les auteurs de cette véridique histoire prirent occasion d'affirmer qu'il devait se nommer Quixada, et non Quesada, comme d'autres ont voulu le faire croire.

Ibid., p. 10.

1 d) On prétend qu'il portait le surnom de Quijada ou Quesada (les auteurs qui ont écrit là-dessus présentent quelques divergences ; cependant de vraisemblables conjectures 
laissent entendre qu'il se nommait Quijana. Mais cela importe peu à notre histoire : il suffit que dans le récit on ne s'écarte pas d'un point de la vérité.

Trad X. de Cardaillac et J. Labarthe, Toulouse, E. Privat éditeur, 1923, p. 22.

[...] il passa huit autres jours à y réfléchir, et finalement il en arriva à s'appeler Don Quichotte. C'est de là, comme il a été dit, que les auteurs d'une si véridique histoire prirent texte pour affirmer qu'il devait, sans aucun doute, se nommer Quijada et non Quesada, comme d'autres ont voulu le prétendre.

Ibid., p. 27.

1 e) On prétend qu'il avait le surnom de Quijada ou de Quesada, car les auteurs qui en ont parlé ne sont pas d'accord sur ce point ; néanmoins, il est probable, d'après les meilleures conjectures, qu'il s'appelait Quejana. Mais cela n'importe guère à notre histoire : il suffit que le récit ne s'écarte sur aucun point de la vérité.

Trad. Francis de Miomandre, Lausanne, « La Guilde du Livre », 1957, p. 21.

[...] et après avoir passé huit jours à y réfléchir, il se trouva enfin celui de don Quichotte ; ce qui a fait penser aux auteurs de cette véridique histoire qu'il devait s'appeler Quijada et non Quesada, ainsi que d'autres l'ont prétendu.

Ibid., p. 24.

$1 \mathrm{f}$ ) On ne sait pas très bien s'il avait nom Quichada ou Quesada (les auteurs qui en ont parlé sont en désaccord sur ce point) ; néanmoins, d'après les conjectures, il est probable qu'il s'appelait Quechana. Mais c'est sans importance pour notre histoire ; il suffit qu'en la racontant on ne s'écarte en rien de la vérité.

Trad. Aline Schulman, Paris, Éditions du Seuil, 1997, p. 43.

[...] et, après y avoir réfléchi pendant huit jours, [il] décida de s'appeler don Quichotte (les auteurs de cette véridique histoire en ont conclu qu'il devait se nommer Quichada, et non Quesada, comme certains l'ont prétendu).

Ibid., p. 46.

1 g) On affirme qu'il avait pour nom Quijada ou Quesada - car, là-dessus, il y a quelque divergence entre les auteurs qui ont écrit à ce sujet -, bien que des conjectures vraisemblables donnent à entendre qu'il s'appelait Quijana. Mais ceci importe peu à notre histoire ; il suffit que dans ce récit, on ne s'écarte pas d'un point de la vérité.

Trad. de J. Canavaggio, C. Allaigre, M. Moner, Paris, Bibl. de la Pléiade, 2001, p. 409.

[...] et dans cette pensée il demeura encore huit jours ; finalement, il en vint à s'appeler don Quichotte : d'où, ainsi qu'il a été dit, les auteurs de cette si véridique histoire ont tiré occasion d'affirmer qu'il devait sans doute s'appeler Quijada, et non Quesada, comme d'autres ont voulu l'assurer.

Ibid. p. 412-413.

$\mathbf{1}$ h) Certains voudraient qu'il eût nom « Quichada » ou " Quesada ». Il y a sur ce point quelque variation parmi les auteurs qui en ont écrit. Cependant des conjectures vraisemblables laissent penser qu'il s'appelait « Quichana ». Mais cela importe peu pour notre histoire : il suffit que le récit ne s'écarte en rien de la vérité.

Trad. Jean-Raymond Fanlo, Paris, La Pochotèque, Le Livre de Poche, 2008, p. 146-147.

[...] [il] passa encore huit jours à y réfléchir au bout desquels il finit par se nommer don Quichotte ; d'où, ainsi qu'on l'a dit, les auteurs de cette si véridique histoire tirèrent argument pour dire qu'il devait sans doute s'appeler Quichada et non Quesada, comme 
d'autres l'ont voulu.

Ibid. p. 149.

1 i) On veut dire qu'il avait le surnom de Quixada ou Quesada (car en ceci il y a quelque différend entre les auteurs qui écrivent de ce fait), encore que par conjectures vraisemblables on pense qu'il s'appelait Quixana ; mais cela importe peu à notre conte : il suffit qu'en la narration d'icelui on ne sorte un seul point de la vérité.

Trad. de C. Oudin, éd. Flammarion, t. I, p. 20.

[...] et en cette pensée il passa huit autres jours, et enfin se vint à appeler don Quichotte ; d'où, comme dit est, les auteurs de cette tant véritable histoire ont pris sujet de dire que sans doute il se devait appeler Quixade, et non pas Quesada, comme d'autres l'ont voulu assurer.

Ibid., p. 23.

\section{La forme en - RA}

2) Desocupado lector, sin juramento me podrás creer que quisiera que este libro, como hijo del entendimiento, fuera el más hermoso, el más gallardo y más discreto que pudiera imaginarse. Pero no he podido yo contravenir á la orden de naturaleza; que en ella cada cosa engendra su semejante. Y así, ¿ qué podía engendrar el estéril y mal cultivado ingenio mío sino la historia de un hijo seco, avellanado, antojadizo, y lleno de pensamientos varios y nunca imaginados de otro alguno...?

[...] Sólo quisiera dártela monda y desnuda, sin el ornamento de prólogo, ni de la inumerabilidad y catálogo de los acostumbrados sonetos, epigramas y elogios que al principio de los libros suelen ponerse. Porque te sé decir que, aunque me costó algún trabajo componerla, ninguno tuve por mayor que hacer esta prefación que vas leyendo.

Ed. Clásicos Castellanos, t. I, p. 7 et p. 9-10.

2 a) Lecteur oisif, tu me pourras bien croire sans serment, j'aurais voulu que ce livre, comme fils de l'entendement, eût été le plus beau, le plus gaillard et le plus ingénieux que l'on eût pu imaginer. Mais je n'ai pu contrevenir à l'ordre de nature, selon lequel chaque chose engendre sa pareille.

[...] Je voudrais seulement te la donner nette et nue, sans ornement de Prologue, et sans ce nombre infini et grand catalogue des sonnets accoutumés, des épigrammes et des éloges, que l'on met ordinairement au commencement des livres. Car je te peux dire qu'encore qu'il m'ait coûté quelque travail à la composer, je n'en ai point trouvé de plus fâcheux que de faire cette préface que tu lis ici.

Trad. de C. Oudin, revue par J. Cassou, éd. cit., p. 51.

2 b) Lecteur oisif, ai-je besoin de te jurer que je voudrais que cet ouvrage fût le plus beau, le plus parfait, le plus agréable des livres? Malheureusement tu sais bien qu'à l'œuvre on reconnaît l'ouvrier

[...] J'aurais seulement désiré pouvoir t'épargner le prologue, l'avant-propos, l'introduction, tout ce bavardage inutile dont aucun auteur ne fait grâce. Trad. de Florian, éd. cit., p. XIII et p. XIV.

2 c) Lecteur inoccupé, tu me croiras bien, sans exiger de serment, si je te dis que je voudrais que ce livre, comme enfant de mon intelligence, fût le plus beau, le plus élégant et le plus spirituel qui se pût imaginer ; mais hélas ! je n'ai pu contrevenir aux lois de la nature, qui veut que chaque être engendre son semblable. 
[...]Seulement, j'aurais voulu te la donner toute nue, sans l'ornement du prologue, sans l'accompagnement ordinaire de cet innombrable catalogue de sonnets, d'épigrammes, d'éloges, qu'on a l'habitude d'imprimer en tête des livres. Car je dois te dire que, bien que cette histoire m'ait coûté quelque travail à composer, aucun ne m'a semblé plus grand que celui de faire cette préface que tu es à lire.

Trad. de L. Viardot, éd. cit., p. 1-2.

2d) Lecteur désœuvré, tu peux m'en croire sans serment, je voudrais que ce livre, comme fils de mon entendement, fût le plus beau, le plus élégant et le plus spirituel qu'on pût concevoir. Mais il ne m'a pas été possible de contrevenir aux lois de la nature ; chez elle, chaque chose procrée chose semblable.

[...] J'aurais voulu seulement te la donner émondée et nue, sans l'orner d'un prologue, ou de cette série innombrable des habituels sonnets, épigrammes et éloges qu'il est d'usage de placer en tête des livres. Car je puis t'affirmer que, s'il m'a fallu quelque effort pour composer cette histoire, rien ne me donne plus de mal que de faire la préface que tu es en train de lire.

Trad. de X. de Cardaillac et J. Labarthe, éd. cit., p. 3.

2 e) Lecteur oisif, tu peux m'en croire sans que je le jure, je voudrais que ce livre, puisque l'enfant de mon cerveau, fût le plus beau, le plus gracieux et le plus sage que l'on fût capable d'imaginer. Mais je n'ai pu contrevenir à l'ordre de la nature, qui veut que chaque chose engendre son semblable.

[...] Je voudrais seulement te l'offrir nette et nue, sans l'ornement d'un prologue, ni cet amas, ce véritable catalogue de sonnets, d'épigrammes et d'éloges qu'on a l'habitude de placer au début des livres. Car, je dois te le dire, quoique la composition de cette histoire m'ait coûté un certain travail, ce n'est rien en comparaison de celui que je m'impose pour rédiger la préface que tu es en train de lire.

Trad. de F. de Miomandre, éd. cit., p. 13.

2 f) Toi qui prendras le temps de me lire, tu peux être assuré, sans exiger de serment, que ce livre, fruit de mon esprit, je l'aurais souhaité le plus beau, le mieux fait, le plus intelligent qui se puisse concevoir. Mais nul ne va contre l'ordre de la nature, qui veut que chaque chose engendre sa pareille.

[...] J'aurais souhaité te la donner toute nue, sans l'orner de prologue ni de l'interminable catalogue de sonnets, d'épigrammes et d'éloges qui figurent habituellement en tête d'un livre. Car je dois t'avouer que, si j'ai eu quelque peine à composer cette histoire, la préface que tu lis m'en a coûté encore davantage.

Trad. d'A. Schulman, éd. cit., p. 25.

2 g) Lecteur oisif, tu pourras bien me croire sans serment :j'aurais voulu que ce livre, comme fils de mon entendement, fût le plus beau, le plus hardi et le plus subtil qui se puisse imaginer. Mais je n'ai pu contrevenir à l'ordre de la nature, qui veut qu'en elle chaque chose engendre sa pareille.

[...] J'aurais voulu te l'offrir nette et nue, sans l'ornement d'un prologue, sans le catalogue infini des habituels sonnets, des épigrammes et des éloges que l'on met d'ordinaire au commencement des livres. Car je puis te dire que, s'il m'a coûté quelque effort pour le composer, aucun ne m'a paru plus grand que de faire cette préface que tu es en train de lire.

Trad. de J. Canavaggio, C. Allaigre, M. Moner, éd. cit., p. 391-392. 
2 h) Lecteur désœuvré, sans serment tu pourras me croire :j'aurais voulu qu'en fils de l'entendement, ce livre fût le plus beau, le plus brillant et le plus intelligent qu'on puisse imaginer. Mais je n'ai pu contrevenir à l'ordre de nature qui veut que chaque chose engendre son semblable.

[...] J'aurais seulement voulu te la donner élaguée, toute nue, sans les accoutrements du prologue et l'interminable liste de rigueur, sonnets, épigrammes, éloges qu'on met d'habitude au début des livres. En effet je peux bien te dire que même s'il m'a coûté quelque travail de le composer, aucun n'a dépassé pour moi celui de faire cette préface que tu es en train de lire.

Trad. de J. R. Fanlo, éd. cit., p. 127.

2 i) Lecteur oisif, tu me pourras bien croire sans en jurer, que j'eusse bien désiré que ce livre, comme fils de l'entendement, eût été le plus beau, le plus gaillard et le plus ingénieux que l'on eût pu imaginer, mais je n'ai pu contrevenir à l'ordre de nature, selon lequel chaque chose engendre sa pareille.

[...] Je voudrais seulement te la donner nette et toute nue, sans ornement de Prologue, et sans ce nombre infini et grand catalogue des sonnets accoutumés, des épigrammes et des éloges, que l'on met ordinairement au commencement des livres. Car je te peux dire qu'encore qu'il m'ait coûté quelque travail à la composer, je n'en ai point trouvé de plus fâcheux que de faire cette préface que tu lis ici.

Trad. de C. Oudin, éd. Flammarion, t. I, p. 13.

\author{
3) Nunca fuera caballero \\ De damas tan bien servido \\ Como fuera don Quijote \\ Cuando de su aldea vino: \\ Doncellas curaban dél; \\ Princesas, del su rocino.
}

o Rocinante ; que éste es el nombre, señoras mías, de mi caballo, y don Quijote de la Mancha el mío ; que, puesto que no quisiera descubrirme fasta que las fazañas fechas en vuestro servicio y pro me descubrieran, la fuerza de acomodar al propósito presente este romance viejo de Lanzarote ha sido causa que sepáis mi nombre antes de toda sazón; pero tiempo vendrá en que las vuestras señorías me manden y yo obedezca, y el valor de mi brazo descubra el deseo que tengo de serviros.

Ibid., chap. II, p. 84-85

3 a) « Oncques n'y eut chevalier,

Si bien des dames servi

Comme le fut don Quichotte

Quand de son village il vint:

Damoiselles le servaient,

Et princesses son coursier.

«Ou Rossinante, car tel est le nom, mesdames, de mon cheval, et don Quichotte de la Manche le mien : car, encore que je n'eusse voulu me découvrir jusqu'à ce que les hautes prouesses faites pour votre service et à mon honneur m'eussent fait connaître, néanmoins la nécessité d'accommoder à la présente matière cette vieille romance de Lancelot a été cause de vous faire savoir mon nom avant l'heure.

Trad. de C. Oudin, revue par J. Cassou, op. cit., p. 78-79. 
3 b) Onc il ne fut de chevalier

Plus en faveur auprès des belles:

Don Quichotte est servi par elles ;

Princesses pansent son coursier...

Il s'appelle Rossinante, madame. Je voulais d'abord que mes seuls exploits vous apprissent que je suis don Quichotte de la Manche ; mais je n'ai pu me refuser à citer dans cette occasion l'ancienne romance de Lancelot.

Trad. de Florian, op. cit., p. 10.

3 c) « Jamais ne fut chevalier si bien servi des dames que don Quichotte quand il vint de son village ; les demoiselles prenaient soin de lui, et les princesses de son rossin », ou Rossinante, car tel est, mesdames, le nom de mon cheval, comme don Quichotte de la Manche est celui de votre serviteur ; et, bien que je ne voulusse pas me découvrir jusqu'à ce que m'eussent découvert les exploits faits en votre service et profit, le besoin d'ajuster à l'occasion présente ce vieux romance de Lancelot a été cause que vous avez su mon nom avant la juste époque.

Trad. de L. Viardot, op. cit., p. 14-15.

$3 \mathrm{~d}$ ) « Oncques chevalier ne se vit aussi bien servi des dames que le fut don Quichotte quand il vint de son village ; des damoiselles prenaient soin de lui, des princesses de son roussin ", ou de Rossinante, car, mesdames, c'est là le nom de mon cheval, et don Quichotte de la Manche, le mien. Quoique j'eusse désiré ne pas révéler mon nom jusqu'à ce que m'eussent révélé les prouesses accomplies par moi à votre service et à votre profit, la nécessité d'accommoder à la circonstance présente ce vieux romance de Lancelot a été cause que vous avez appris ce nom avant l'heure voulue.

Trad. de X. de Cardaillac et J. Labarthe, op. cit., p. 36.

3 e) « Jamais ne fut si bien soigné

Par nulle dame un chevalier

Que don Quichotte quand il vint

De son village en ce château.

Il était servi par des dames

Er son cheval par des princesses. »

"C'est-à-dire Rossinante ! car tel est le nom de mon cheval, mes belles dames, et don Quichotte de la Manche est le mien, que je n'avais l'intention de découvrir qu'après avoir accompli pour votre service quelque action qui m'eût révélé. La nécessité d'appliquer au cas présent cette vieille chanson de Lancelot a été cause que vous l'avez su avant le temps. Trad. de F. de Miomandre, op. cit., p. 30.

$3 \mathrm{f})$ Jamais ne fut chevalier

De dames si bien soigné

Que ne le fut don Quichotte

Quand de son village il vint.

Les suivantes le servaient,

Les princesses son roussin,

«... ou Rossinante, car tel est le nom de mon cheval, mes nobles dames, comme don

Quichotte de la Manche est le mien. Et bien que je n'aie pas voulu me découvrir avant que les exploits accomplis pour votre service ne me découvrent d'eux-mêmes, la nécessité d'appliquer au cas présent cette vieille chanson de Lancelot a été cause que vous ayez su 
mon nom avant l'heure.

Trad. d'A. Schulman, op. cit., p. 52.

3 g) Oncques n'y eut chevalier

Si bien servi par les dames,

Comme le fut don Quichotte,

Quand de son village il vint.

Damoiselles le servaient

Et princesses son roussin.,

lequel s'appelle aussi Rossinante, car tel est, mesdames, le nom de mon cheval, tandis que don Quichotte est le mien. Car, bien que je n'eusse pas voulu me découvrir avant que ne me découvrent les prouesses accomplies pour votre service et votre profit, la nécessité d'accommoder à la présente circonstance ce vieux romance de Lancelot vous a fait savoir mon nom avant l'heure.

Trad. de J. Canavaggio, C. Allaigre, M. Moner, op. cit., p. 418.

3 h) - Jamais ne fut chevalier / De dames si bien aidé / Comme le fut don Quichotte / Quand de son pays il vint : / Demoiselles à ses bottes : / Princesses pour son roussin... ou Rossinante, car tel est le nom, mesdames, de mon cheval, et don Quichotte de la Manche est le mien; et bien que point n'eusse voulu me découvrir avant que me découvrissent les exploits faits à vos service et profit, la nécessité d'accommoder aux circonstances présentes ce vieux romance de Lanzarote fut cause que vous sussiez mon nom avant saison.

Trad. J. R. Fanlo, op. cit., p. 155.

3 i) « Jamais il n'y a eu chevalier si bien des dames servi comme le fut don Quichotte : lorsque de son village il vint, damoiselles avaient soin de lui, et princesses de son coursier, ou Rossinante, car tel est le nom, mesdames, de mon cheval, et don Quichotte de la Manche est le mien : car, encore que je n'eusse voulu me découvrir jusqu'à ce que les hautes prouesses faites pour votre service et pour moi m'eussent fait connaître, néanmoins la nécessité d'accommoder à la présente matière ce vieux roman de Lancelot a été cause de vous faire savoir mon nom avant l'heure.

Trad. de C. Oudin, op. cit., p. 28-29.

4) - Todo el mundo se tenga, si todo el mundo no confiesa que no hay en el mundo todo doncella más hermosa que la Emperatriz de la Mancha, la sin par Dulcinea del Toboso.

Paráronse los mercaderes al son destas razones, y á ver la extraña figura del que las decía, y por la figura y por las razones luego echaron de ver la locura de su dueño; mas quisieron ver despacio en qué paraba aquella confesión que se les pedía, y uno de ellos, que era un poco burlón y muy mucho discreto, le dijo :

- Señor caballero, nosotros no conocemos quién sea esa buena señora que decís; mostrádnosla : que si ella fuere de tanta hermosura como significáis, de buena gana y sin apremio alguno confesaremos la verdad que por parte vuestra nos es pedida.

- Si os la mostrara - replicó don Quijote -, ¿ qué hiciérades vosotros en confesar una verdad tan notoria? La importancia está en que sin verla lo habéis de creer, confesar, afirmar, jurar y defender; donde no, conmigo sois en batalla, gente descomunal y soberbia. Que, ahora vengáis uno á uno, como pide la orden de caballería, ahora todos juntos, como es costumbre y mala usanza de los de vuestra ralea, aquí os aguardo y espero, confiado en la razón que de mi parte tengo. 
- Señor caballero - replicó el mercader -, suplico á vuestra merced en nombre de todos estos príncipes que aquí estamos que, porque no encarguemos nuestras conciencias confesando una cosa por nosotros jamás vista ni oída, y más siendo tan en perjuicio de las emperatrices y reinas del Alcarria y Extremadura, que vuestra merced sea servido de mostrarnos algún retrato de esa señora, aunque sea tamaño como un grano de trigo ; que por el hilo se sacará el ovillo, y quedaremos con esto satisfechos y seguros, $y$ vuestra merced quedará contento y pagado; $y$ aun creo que estamos ya tan de su parte, que, aunque su retrato nos muestre que es tuerta de un ojo y que del otro le mana bermellón y piedra azufre, con todo eso, por complacer á vuestra merced, diremos en su favor todo lo que quisiere.

- No le mana, canalla infame - respondió don Quijote encendido en cólera -; no le mana, digo, eso que decís, sino ámbar y algalia entre algodones; y no es tuerta ni corcovada, sino más derecha que un huso de Guadarrama. Pero ; vosotros pagaréis la grande blasfemia que habéis dicho contra tamaña beldad como es la de mi señora!

Clásicos Castellanos, t. I, chap. IV, p. 125-129.

4 a) - Si je ne vous l'avais montrée, répliqua don Quichotte, que feriez-vous en confessant une vérité si évidente ! Le fin de l'histoire est que sans la voir vous le devez croire, confesser, affirmer, jurer et défendre...

Trad. de C. Oudin, revue par J. Cassou, op. cit., p. 92-93.

4 b) - Vraiment ? reprit don Quichotte; si vous la voyiez, où serait le mérite de la trouver belle? L'important c'est que sans l'avoir vue vous en soyez sûrs, le disiez, l'affirmiez, le juriez, et le souteniez.

Trad. de Florian, op. cit., p. 20.

4 c) - Si je vous la faisais voir, répliqua don Quichotte, quel beau mérite auriez-vous à confesser une vérité si manifeste ? L'important, c'et que, sans la voir, vous le croyiez, confessiez, affirmiez, juriez et souteniez les armes à la main.

Trad. de L. Viardot, op. cit., p. 24.

4 d) - Si je vous la montrais, répliqua don Quichotte, quel mérite auriez-vous à confesser vérité si notoire ? L'important est que, sans la voir, vous devez croire cela, le reconnaître, l'affirmer, le jurer et le soutenir.

Trad. de X. de Cardaillac et J. Labarthe, op. cit., p. 53.

4 e) - Si je vous la montrais, répliqua don Quichotte, quel mérite auriez-vous à reconnaître une vérité si évidente ? L'important est de le croire sans le voir ; de le confesser, de l'affirmer, de le jurer, de le soutenir envers et contre tous.

Trad. de F. de Miomandre, op. cit., p. 42.

4 f) - Si je vous la montrais, quel mérite auriez-vous à reconnaître une vérité aussi manifeste ? L'important est de le croire sans la voir ; et de le confesser, de l'affirmer, de le jurer, de le soutenir les armes à la main.

Trad. d'A. Schulman, op. cit., p. 64.

4 g) - Si je vous la montrais, répliqua don Quichotte, que vous servirait de confesser une vérité aussi notoire ? L'important est que, sans l'avoir vue, vous le devez croire, confesser, affirmer, jurer et soutenir.

Trad. de J. Canavaggio, C. Allaigre, M. Moner, op. cit., p. 431.

4 h) - Si je vous la montrais, que servirait que vous confessiez une vérité si évidente? Le point est que sans la voir vous avez à le croire, confesser, affirmer, jurer et défendre ! Trad. de J. R. Fanlo, op. cit., p. 167. 
4 i) - Si je vous l'avais montrée, répliqua don Quichotte, que feriez-vous en confessant une vérité si notoire ? L'important est que sans la voir vous le devez croire, confesser, affirmer, jurer et défendre.

Trad. de C. Oudin, op. cit., p. 40.

\section{Yantar}

5) ... sólo le preguntaron si quería comer alguna cosa.

- Cualquiera yantaría yo - respondió don Quijote -, porque, á lo que entiendo, me haría mucho al caso.

Don Quijote, éd. cit., t. I, chap. II, p. 85.

5 a) ... seulement elles lui demandèrent s'il voulait manger quelque chose. « Oui-da, je me sustenterais bien de quoi que ce soit, répondit don Quichotte, car, à ce qu'il m'en semble, il me viendrait fort à propos. "

Trad. de C. Oudin, revue par J. Cassou, éd. cit., p. 79.

5 b) Elles lui demandèrent enfin s'il voulait manger quelque chose. Il répondit franchement qu'il avait besoin de dîner. Comme c'était un vendredi....

Trad. de Florian, éd. cit., p. 10.

5 c) Elles lui demandèrent s'il voulait manger quelque chose. «Quoi que ce fût, je m'en accommoderais, répondit don Quichotte ; car, si je ne me trompe, toute chose viendrait fort à point. »

Trad. de L. Viardot, éd. cit., p. 15.

$5 \mathrm{~d}$ ) Elles lui demandèrent simplement s'il voulait manger un morceau. «Je prendrai n'importe quoi, répliqua-t-il, car, je le sens, cela viendrait bien à propos pour moi. » Trad. X. de Cardaillac et J. Labarthe, éd. cit., p. 36.

5 e) Elles se contentèrent de demander à notre chevalier s'il voulait manger quelque chose.

- N'importe quoi, dit don Quichotte, et je crois que ça tomberait bien.

Trad. F. de Miomandre, éd. cit., p. 30.

$5 \mathrm{f})$... et se contentèrent de lui demander s'il voulait manger quelque chose.

- Je goûterai à tout ce que vous daignerez m'offrir de vos blanches mains, répondit don Quichotte; si je ne me trompe, cela viendra fort à point.

Trad. d'A. Schulman, éd. cit., p. 52-53.

$5 \mathbf{g})$... elles lui demandèrent seulement s'il voulait manger quelque chose.

"N'importe quoi, répondit don Quichotte ; car, à ce que j'entends, cela viendrait à point pour moi. $»$

Trad. de J. Canavaggio, C. Allaigre, M. Moner, éd. cit., p. 419.

5 h) Elles lui demandèrent seulement s'il voulait manger quelque chose.

- De toute chose je me sustenterai, parce que j'ai comme idée que ça me ferait vraiment l'affaire.

Trad. J. R. Fanlo, éd. cit., p. 155.

5 i) ... seulement elles lui demandèrent s'il voulait manger quelque chose. «Oui-da, je prendrais bien quoi que ce soit, répondit don Quichotte, car, à ce qu'il m'en semble, il me 
viendrait fort à propos. »

Trad. de C. Oudin, éd. Flammarion, p. 29.

5 j) Quelle chose que soit bien voulentiers m'en desjeuneroys, car, à ce que m'en semble, elle me viendroit moult à propos.

- De toute chose bien voulentiers me desjeuneroys...

- De quelque chere [quelque viande] que soit me contenteroys...

\section{L'apostrophe aux mozas}

6) - Non fuyan las vuestras mercedes, ni teman desaguisado alguno; ca á la orden de caballería que profeso non toca ni atañe facerle á ninguno, cuanto más á tan altas doncellas como vuestras presencias demuestran.

[...] - Bien parece la mesura en las fermosas, y es mucha sandez, además, la risa que de leve causa procede; pero non vos lo digo porque os acuitedes ni mostredes mal talante; que el mío non es de ál que de serviros.

El lenguaje, no entendido de las señoras...

Don Quijote, Clásicos Castellanos, t. I, chap. II, p. 79.

6 a) « Que Vos Grâces ne fuient pas ni ne craignent qu'on leur fasse déplaisir aucun, car il n'appartient ni n'est bienséant à l'ordre de chevalerie, dont je fais profession, de faire tort à personne, combien moins à de si hautes damoiselles comme vos personnes le démontrent.

[...] La modestie est bienséante aux belles et c'est grande folie que le rire qui de cause légère procède ; mais je ne vous le dis pas afin que vous vous en affligiez ou montriez du mécontentement, car mon intention n'est autre que de vous servir. » Ce langage, qui n'était point entendu par ces dames...

Trad. de C. Oudin, revue par J. Cassou, éd. cit., p. 76-77.

6 b) « Rassurez-vous, leur dit-il, en leur montrant sous sa visière de carton un visage sec et poudreux, vos seigneuries n'ont rien à craindre : les lois de la chevalerie, que je fais profession de suivre, me défendent d'offenser personne, et me prescrivent surtout d'être aux ordres des demoiselles aussi respectables que vous. "

[...] « Mesdames, reprit don Quichotte, presque fâché, il ne suffit pas d'être belles, il faut encore être réservées, et surtout ne pas rire sans sujet. Daignez excuser cet avis de la part d'un homme qui ne désire que de vous servir. » Ce langage, fort étranger aux jeunes filles...

Trad. de Florian, éd. cit., p. 9.

6 c) Que Vos Grâces ne prennent point la fuite, et ne craignent nulle discourtoise offense ; car, dans l'ordre de chevalerie que je professe, il n'appartient ni ne convient d'en faire à personne, et surtout à des damoiselles d'aussi haut parage que le démontrent vos présences.

[...] La politesse sied à la beauté, et le rire qui procède d'une cause légère est une inconvenance ; mais je ne vous dis point cela pour vous causer de la peine, ni troubler votre belle humeur, la mienne n'étant autre que de vous servir.

Ce langage, que ne comprenaient point les dames...

Trad. L. Viardot, éd. cit., p. 13-14.

6 d) Que vos grâces ne s'enfuient pas ; qu'elles ne redoutent aucune offense, car à l'ordre de chevalerie que je professe il n'appartient pas et il ne sied pas d'en faire à personne, 
encore moins à des damoiselles d'un rang aussi élevé que votre extérieur le révèle. [...] La juste mesure convient aux belles, déclara-t-il, et, de plus, c'est grande sottise que de rire pour des motifs futiles, mais je ne vous dis pas cela pour que vous vous fâchiez et témoigniez de malveillantes dispositions ; les miennes ne tendent qu'à vous servir. Ce langage incompris de nos dames...

Trad. de X. de Cardaillac et J. Labarthe, éd. cit., p. 33-34.

6 e) - Ne fuyez pas nobles demoiselles, vous n'avez rien à craindre ; l'ordre de chevalerie, dont je fais profession, me défend d'offenser personne, et moins encore de hautes dames comme vous.

[...] La retenue sied aux belles, et c'est d'ailleurs grande sottise que de rire à propos de rien. Je ne dis pas cela, mesdemoiselles, pour vous offenser, car je n'ai point d'autre intention que de vous servir.

Un tel langage, si nouveau pour ces dames...

Trad. de F. de Miomandre, éd. cit., p. 28-29.

6 f) Ne fuyez point, gentes demoiselles, vous n'avez rien à craindre ; je suis chevalier errant, et l'ordre dans lequel je professe m'interdit d'offenser personne, et moins encore des dames d'aussi haut rang.

[...] La retenue sied aux belles, dit-il, et c'est grande sottise que de rire à propos de rien. Je ne vous dis point cela pour vous chagriner ou vous mettre de méchante humeur, car je n'ai d'autre intention que de vous servir.

Un tel langage, auquel elles ne comprenaient rien...

Trad. d'A. Schulman, éd. cit., p. 50-51.

6 g) « Que Vos Grâces ne s'enfuient ni ne craignent la moindre discourtoisie ; car à l'ordre de chevalerie dont je fais profession il n'appartient ni ne sied d'en faire à personne ; et moins encore à de si hautes damoiselles comme leur présence le démontre. »

[...] La modestie est bienséante aux belles et, qui plus est, rien n'est plus sot que le rire qui naît d'une cause futile. Mais je ne vous dis point cela pour que vous vous en affligiez et me montriez méchante humeur ; car la mienne n'est autre que de vous servir. » Ce langage, inconnu de nos dames...

Trad. de J. Canavaggio, C. Allaigre, M. Moner, éd. cit., p. 417.

6 h) - Ne fuyez, grâces vôtres, ni ne craignez offense, si vrai est que l'ordre de chevalerie que professe ne revient ni ne sied en faire à quiconque, que non pas à si hautes damoiselles comme vos personnes démontrent.

[...] La mesure sied aux belles, outre qu'est grande sottise le rire qui de cause légère procède ; mais cela ne soit dit pour vous peiner ni montrer disposition mauvaise, car la mienne n'est autre que de vous servir.

Le langage que ces dames n'entendaient pas...

Trad. de J. R. Fanlo, éd. cit., p. 153.

6 i) Que Vos Grâces ne fuient pas ni ne craignent qu'on leur fasse aucun déplaisir, car il n'appartient ni n'est bienséant à l'ordre de chevalerie, dont je fais profession, de faire aucun tort à personne, combien moins à de si hautes damoiselles comme vos personnes le démontrent.

[...] Le beau maintien et modestie est bienséant aux belles ; c'est un argument de grande folie aux dames que le rire qui procède d'une légère cause ; mais je ne vous le dis pas afin que vous vous en affligiez ou montriez du mécontentement, car mon intention n'est autre que de vous rendre service. 
Le langage, qui n'était point entendu par ces dames...

Trad. de C. Oudin, éd. Flammarion, p. 27.

$6 \mathbf{j})$...et crainte n'ayez qu'on vous offense; car à l'ordre de chevalerie que je professe n'est escheu ni devolu de le fayre aulcunement [...] ; mais ce ne vous dy pour vostre tourment ni pour qu'ayez mauvais talent; car n'ay desir ni affaire fors que de vous servir [fors que mon service vous plaise].

\section{L'invocation à Dulcinée}

7) ¡ Oh princesa Dulcinea, señora deste cautivo corazón! Mucho agravio me habedes fecho en despedirme y reprocharme con el riguroso afincamiento de mandarme no parecer ante la vuestra fermosura. Plégaos, señora, de membraros deste vuestro sujeto que tantas cuitas por vuestro amor padece.

Don Quijote, Clásicos Castellanos, t. I, I, cap. II, p. 72-73.

7 a) « Ô princesse Dulcinée, dame de ce chétif cœur, vous m’avez fait grand grief de me chasser et me blâmer avec tant de rigueur, en me commandant de ne paraître jamais plus devant votre beauté. Plaise à vous, madame, de vous remémorer de cestui cœur de votre sujet qui tant de misères endure pour votre amour. " Trad de C. Oudin, revue par J. Cassou, éd. cit., p. 75.

7 b) Et vous, princesse Dulcinée, souveraine de ce cœur captif, ah, vous l'avez blessé mortellement par votre injuste colère, par cette défense terrible d'oser me montrer à vos yeux ; hélas ! n'oubliez pas du moins l'infortuné qui souffre pour vous.

Trad. de Florian, éd. cit., p. 8.

7 c) «O princesse Dulcinée, dame de ce cœur captif! une grande injure vous m'avez faite en me donnant congé, en m'imposant, par votre ordre, la rigoureuse contrainte de ne plus paraître en présence de votre beauté. Daignez, ma dame, avoir souvenance de ce cœur, votre sujet, qui souffre tant d'angoisses pour l'amour de vous. »

Trad. de L. Viardot, éd. cit., p. 12.

7 d) O princesse Dulcinée, souveraine de ce cœur captif, vous m'avez causé un grand tort en me congédiant et en me repoussant, avec cette injonction rigoureuse de ne plus paraître devant votre beauté. Condescendez, madame, à vous remémorer ce cœur, votre vassal, qui souffre tant d'afflictions pour l'amour de vous.

Trad. de X. de Cardaillac et J. Labarthe, éd. cit., p. 32.

7 e) O princesse Dulcinée ! s'écria-t-il, dame de ce cœur esclave, vous m'avez fait une grande injustice en me bannissant de votre présence, et en m'ordonnant avec tant de rigueur de ne jamais me présenter devant votre beauté. Veuillez vous souvenir, dame de mes pensées, de ce cœur qui vous appartient, et qui a tant souffert pour l'amour de vous. Trad. F. de Miomandre, éd. cit., p. 27.

7 f) Ô, princesse Dulcinée, souveraine de mon cœur ! C'est grande offense que vous me fites en me bannissant de votre présence et en m'ordonnant avec tant de rigueur de ne plus paraître devant votre beauté. Puissiez-vous, madame, ne pas oublier ce cœur par vous asservi, et pour l'amour de vous souffrant mille peines.

Trad. A. Schulman, éd. cit., p. 49.

7 g) Ô princesse Dulcinée, dame de ce cœur captif! Vous m'avez fait grand tort en me donnant congé et en me chassant, avec l'injonction rigoureuse de ne plus paraître devant 
votre beauté. Daignez, madame, avoir souvenance de ce cœur qui vous est soumis et qui souffre tant de misères pour l'amour de vous.

Trad. de J. Canavaggio, C. Allaigre, M. Moner, éd. cit., p. 415.

7 h) - Ô princesse Dulcinée, maîtresse de mon cœur prisonnier ! Bien grand dommage m'avez fait, m'exilant, m'incriminant en rigoureuse injonction de ne plus paraître devant votre beauté ! Plaise à vous, Dame, vous ramentevoir ce cœur votre serf, qui tant de maux pour votre amour pâtit.

Trad. J. R. Fanlo, éd. cit., p. 152.

7 i) « O princesse Dulcinée, dame de ce chétif cœur, vous m’avez fait un grand grief de me chasser et me reprocher avec tant de rigueur, en me commandant de ne paraître jamais plus devant votre beauté. Plaise à vous, madame, de vous remémorer de cestui cœur de votre sujet qui souffre tant de misères pour votre amour ».

Trad. de C. Oudin, éd. Flammarion, p. 25-26.

7 j) Ô princesse Dulcinée, maistresse [souveraine] de ce cueur prisonnier [chetif], fort grand oultrage [dommaige] m'avez faict lors mesme que m'avez debouté [banni, rebouté] et remonstré, vous qui avecques tant grand rigueur m'avez par devers vostre beaulté requis [enjoinct] de ne poinct paroistre. Plaise à vous, ma Dame, de vous remembrer [recorder, ramentevoir] celuy qui sa vie a en vostre mercy close et tout meurdry de vostre Amour se treuve.

\section{La lettre à Dulcinée}

8) Soberana y alta señora:

El ferido de punta de ausencia y el llagado de las telas del corazón, dulcísima Dulcinea del Toboso, te envía la salud que él no tiene. Si tu fermosura me desprecia, si tu valor no es en mi pro, si tus desdenes son en mi afincamiento, maguer que yo sea asaz de sufrido, mal podré sostenerme en esta cuita, que, además de ser fuerte, es muy duradera. [...] ... si gustares de acorrerme, tuyo soy ; y si no, haz lo que te viniere en gusto; que con acabar mi vida habré satisfecho á tu crueldad y á mi deseo.

Tuyo hasta la muerte.

Don Quijote, Clásicos Castellanos, t. II, chap. XXV, p. 313-314.

8 a) Souveraine et haute Dame,

Le féru de la pointe d'absence et le navré au fond du cœur, très douce Dulcinée du Toboso, t'envoie la santé qu'il n'a pas. Si ta beauté me dédaigne, si ta valeur n'est pas à mon profit, si tes dédains sont à mon détriment, encore que je sois assez patient, je pourrai mal me soutenir en cette affliction, car, outre qu'elle est pénible, elle est fort durable. [...] ... si tu as envie de me secourir, je suis à toi, et sinon, fais ce que te plaira, car, en finissant ma vie, j'aurai satisfait à ta cruauté et à mon désir.

A toi jusqu'à la mort.

Trad. de C. Oudin, revue par J. Cassou, éd. cit., p. 293.

8 b) Haute et souveraine dame,

Celui qui languit loin de vous, celui dont le cœur, profondément blessé, souffre et chérit ses souffrances, vous souhaite, douce Dulcinée, le repos qu'il a perdu. Si votre beauté me dédaigne, si votre fierté me rebute, je succomberai, malgré ma constance, sous le poids de mes douleurs. [...] Mes tristes jours sont à vous. Un mot peut les conserver, un mot aussi peut les finir. Commandez, il me sera doux de satisfaire votre cruauté. 
Le vôtre jusqu'à la mort.

Trad. de Florian, éd. cit., p. 130-131.

8 c) Haute et souveraine dame,

Le piqué au vif des pointes de l'absence, le blessé de l'intime région du cœur, dulcissime Dulcinée du Toboso, te souhaite la bonne santé dont il ne jouit plus. Si ta beauté me dédaigne, si tes mérites cessent d'être portés en ma faveur, et si tes rigueurs entretiennent mes angoisses, bien que je sois passablement rompu à la souffrance, mal pourrai-je me maintenir en une transe semblable, qui n'est pas seulement forte, mais durable à l'avenant. [...] S'il te plaît de me secourir, je suis à toi ; sinon, fais à ta fantaisie, car, en terminant mes jours, j'aurai satisfait à mon désir et à ta cruauté.

A toi jusqu'à la mort.

Trad. de L. Viardot, éd. cit., p. 167.

8 d) Souveraine et éminente dame. Celui qui est frappé par la pointe de l'absence et blessé dans tous les replis de son cœur, dulcissime Dulcinée du Toboso, en te saluant te souhaite la santé qu'il n'a plus. Si ta beauté me dédaigne, si ton mérite ne vient pas à mon aide, si tes rigueurs s'exercent à mon détriment, en dépit de ma grande résignation il me sera difficile de résister à cette affection qui, déjà très pénible, est en outre fort persistante. [...] ... s'il te plait de venir me secourir, je t'appartiens; sinon fais ce qui te conviendra le mieux ; avec la fin de ma vie j'aurai donné satisfaction à ta cruauté et à mes désirs.

A toi jusqu'à la mort.

Trad. de X. de Cardaillac et J. Labarthe, éd. cit., p. 298.

8 e) Souveraine et haute dame,

Celui que blesse ton absence, celui dont la membrane du cœur est déchirée, ô très douce Dulcinée du Toboso, t'envoie les vœux d'une santé qu'il n'a plus. Si ta beauté me méprise, si ton mérite se détourne de moi, si tes dédains m'accablent, malgré que je sois assez patient, je ne pourrai pas supporter ce chagrin, car, outre qu'il est trop fort, il est aussi de trop longue durée. [...] S'il te plaît de me secourir, je suis à toi ; sinon, fais ce que tu voudras, et j'en finirai avec cette vie satisfaisant ainsi ta cruauté et mon désir.

A toi, jusqu'à la mort.

Trad. de F. de Miomandre, éd. cit., p. 208.

8 f) Haute et souveraine dame,

Celui que ton absence blesse au plus profond, celui dont le cœur est déchiré jusqu'au tréfonds, te souhaite, ô douce Dulcinée du Toboso, la bonne santé qu'il n'a plus. Si ta beauté à mes yeux se refuse, si ta noblesse ses faveurs m'interdit, si tes rigueurs à mes plaintes répondent, bien que je sois patient outre mesure, je ne saurais supporter cette douleur extrême, que depuis trop longtemps j'endure. [...] s'il te plait de me secourir, je suis à toi ; sinon fais-en selon ton caprice car, en mettant un terme à mes jours, j'aurai au moins satisfait à ta cruauté et à mon désir.

A toi jusqu'à la mort.

Trad. d'A. Schulman, éd. cit., p. 245-246.

$8 \mathrm{~g}$ ) Suzeraine et haute dame,

Celui qui est féru par la pointe d'absence et déchiré dans les replis de son cœur, très douce Dulcinée du Toboso, te salue et te désire la santé dont il ne jouit plus. Si ta beauté me dédaigne, si ta valeur ne me vient plus en aide, si tes rigueurs sont à mon détriment, encore que je sois assez patient, je pourrai mal me soutenir en cette transe qui, outre 
qu'elle est rude, est fort durable. [...] Si jamais il te plaisait de me secourir, je suis à toi ; et sinon, fais ce qu'il te plaira : en mettant un terme à ma vie, j'aurai satisfait à ta cruauté et à mon désir.

A toi jusqu'à la mort.

Trad. de J. Canavaggio, C. Allaigre, M. Moner, éd. cit., p. 607.

8 h) Dame souveraine et haute,

Le navré que point l'absence, le blessé en la chair même de son cœur, te souhaite le bien que lui n'a pas, très douce Dulcinée du Toboso. Si ta beauté me dédaigne, si ta valeur me fuit, si tes mépris veulent ma souffrance, encore que je sois patient assez, mal pourrai-je subsister en cette peine, dure et plus que dure, longue. [...] S'il te plaisait me secourir, je suis tien. Autrement, fais ce qu'il te plaira : finissant mes jours, j'aurai satisfait à ta cruauté comme à mon désir.

Tien jusqu'à la mort.

Trad. de J. R. Fanlo, éd. cit., p. 353-354.

8 i) Souveraine et haute dame,

Le féru de la pointe d'absence et le blessé aux toiles du cœur, très douce Dulcinée du Toboso, t'envoie la santé qu'il n'a pas. Si ta beauté me dédaigne, si ta valeur n'est pas à mon profit, si tes dédains sont à mon angoisse, encore que je sois assez patient, je pourrai mal me soutenir en cette affliction, car, outre qu'elle est forte, elle est fort durable. [...] ... si tu as envie de me secourir, je suis à toi, et sinon, fais ce qu'il te plaira, car, en finissant ma vie, j'aurai satisfait à ta cruauté et à mon désir.

A toi jusqu'à la mort.

Trad. de C. Oudin, éd. Flammarion, t. I, p. 203.

$8 \mathbf{j})$ Le navré [le feru] de la poincture de l'absence et le playé jusques au fond du cueur, trop plus que doulce Dulcinée du Toboso, vous [te] mande l'heur qui tollu luy a esté [vous souhaite la santé que n'a poinct]. [...] ... combien que plus assez je sois souffrant, mal me pourray soustenir en ce dueil [tourment] qui, oultre que fort, me dure. [...] S'il vous plaist me donner secours [Si vous agrée me secourir], je suis vostre et vostre me tiens; et sy non, faites ce qui en vostre gré sera.

- Celluy que poingt l'absence \& celluy qui au tresfonds du cueur est navré [playé]...

- Celluy que picque dru l'absence \& celluy qu'Amour au tresfonds de son cueur a mordu...

- Qui du dard de l'absence est feru [navré] \& au tresfonds de son cueur playé...

- ...combien que plus assez je sois souffrant, mal me pourray soustenir en ce dueil [ce tourment] qui, oultre que fort, me dure[est durable].

- S'il vous plaist me donner secours [Sy vous agrée me secourir], je suis vostre et vostre me tiens; et sy non, faictes ce qui en vostre gré sera.

\section{NOTES}

1. Cervantès, Don Quichotte précédé de La Galatée, trad. de J. Canavaggio, C. Allaigre, M. Moner, Paris, Bibl. de la Pléiade, 2001, t. I, p. LXXIV.

2. Cf. E. Alarcos Llorach, Fonología española, Madrid, Gredos, 1968, p. 264 . Voir aussi p. 271-272 : « La velarización de /š/ no penetró en las hablas leonesas, ni en el dominio catalán, ni en las zonas del aragonés pirenaico no catellanizado. Por otro lado, los testimonios de velarización son relativamente tardíos [...] Durante el siglo XVI son inequívocos los testimonios de su carácter palatal, con frecuentes equiparaciones con la pronunciación italiana o francesa: / š / como en francés chevalier, como italiano poscia, pesci. » 
3. Ibid., p. 272 : « /s, z/, ápico-alveolares casi palatales, estaban muy cerca del punto articulatorio de /š, $\check{z} / . »$

4. Cf. R. Menéndez Pidal, Manual de gramática histórica española, undécima edición, Madrid, 1962, § 37b, p. 119. Cf. aussi, E. Alarcos Llorach, op. cit., p. 266. Le caractère apical du [s] castillan, qui se traduit par un chuintement, a provoqué de telles confusions dès les premiers temps de la langue (le latin SAPONE devient xabon en castillan médiéval) et tout au long du Moyen Âge la langue enregistre de telles confusions (les tiseras maniées par don Juan Manuel sont devenues des tixeras pour López de Ayala, par exemple).

5. Cf. R. Menéndez Pidal, op. cit., § 72.2, p. 197.

6. Cf. Covarrubias, cité par R. Menéndez Pidal, op. cit., p. 197 : «... los aldeanos dicen maxcara, pronunciando como árabes la xin, y guardan más la antigüedad. »

7. Coquille ou libre choix (à moins qu'il ne suive la première édition de Cuesta), Miomandre innove, comme pour ajouter à l'hésitation ou à son étendue, et modifie la troisième forme : Quejana. Par la voyelle - e- il la relie à Quesada; par la consonne -j-il conserve le lien avec Quijada. Il multiplie les termes du choix ; il n'aide pas le lecteur français à comprendre les raisons du doute et la matière qui le porte. Les traducteurs de $1 \mathrm{~g}$ ont, eux, souci dans une longue notice de s'arrêter sur ces noms (p. 1498-1499), mais ils n'en commentent que le contenu et jamais la matérialité phonique. Et - ce qui est remarquable - ce commentaire, autorisé par le texte original, ne trouverait pas à s'appuyer sur la traduction.

8. Insoucieux des prononciations de l'original et s'en remettant à la graphie d'origine, l'anglais, selon sa propre règle, dit Don Quixote ['dan 'kwiksaut].

9. Cf. cité par J. Corominas, D.C.E.L.C., s. v. Marión : «[quizote] parece hallarse en Gonzalo Correas (1627) : "el quizote y el marión por Agosto pierden sazón (entiende que son pescados)", aunque no conozco un pez llamado quizote. "

10. Cf. cité par J. Corominas, Ibid., s. v. Alquicel : « Venía toda la sierra cubierta de moros, e traían todos quezotes vermejos y las barbas y los cabellos alfeñados » (Crón. de Juan II (h. 1460), ed. Rivad. LXVIII, 319). - « ... el cast. ant. Quezote 'alquicel' (vestidura morisca a modo de capa) [...] junto con el gascón pirenaico quesso (quessa) 'camisa' y el cat. ant. y mall. Cassot 'especie de camiseta de tela de saco empleada para trabajar'. »

11. Quesada, selon J. Corominas (D.C.E.L.C.), n'entre au dictionnaire de l'Académie qu'au XIX ${ }^{\mathrm{e}}$ siècle.

12. Cf. M. Moliner, Diccionario de uso del español, s. v. Sobrenombre: "1) Nombre calificativo que, a veces, se añade al nombre de una persona : "El Católico" es el sobrenombre del rey Fernando V ".

13. Ibid. : «2) Apodo o cualquier nombre que se emplea para nombrar a una persona en vez del suyo propio .»

14. Cf. entre autres, Diccionario Planeta de la lengua española usual (dir. F. Marsá), MadridBarcelone, 1989, et M. Seco, O. Andrés, G. Ramos, Diccionario del español actual, Madrid, 1999.

15. Dictionnaire universel. Cf. aussi : «Comme on appelle moy et mes freres les Estiennes du surnom de notre pere. » (Henri Estienne, Conformité du langage françois avec le grec, Paris, éd. Feugère, 1853, p. 52).

16. Cf. aussi A. de Nebrija : «Sobrenombre : cognomen, - mentum ».

17. Il n'est pas sans intérêt de relever dans les dictionnaires que les exemples de surnom hors de la valeur de "sobriquet » sont tous au XIX ${ }^{\mathrm{e}}$ siècle de la plume d'historiens ou de lexicographes.

18. « Ath. : Comment vous nommez-vous? - Joas : J'ai nom Éliacin. » (Act. II, sc. 7).

19. Les raisons qui ont fait hésiter les traducteurs sont celles, aussi, qui font choisir de désigner par son signifiant ce «temps verbal», et en tout premier lieu de rejeter la dénomination « imparfait du subjonctif » dont l'impropriété est flagrante. G. Guillaume, à propos du subjonctif français, critique également cette terminologie et en montre l'inadéquation; voir Leçons de linguistique de G. Guillaume, 1945-1946 A, vol. 7, Presses univ. de Lille et Presses de l'Univ. LavalQuébec, 1987, p. 57. 
20. On trouvera une explication plus développée du problème dans Marie-France Delport, « Los herederos españoles del perfectum latino: conservación y reinterpretación en romance. », Chréode, $\mathrm{n}^{\circ}$ 2, vol. 1, printemps 2009, Éditions Hispaniques (à paraître).

21. Cervantès peut, cependant, en avoir une connaissance passive, la comprendre chez des sujets parlants plus jeunes ou plus perméables à une évolution qui, effectivement, ne va pas tarder à s'imposer.

22. Cf. Ángel Rosenblat, La lengua del «Quijote », « Remedo de la lengua antigua », Madrid, ed. Gredos, 1978, p. 26-32.

23. Maurice Molho, De Cervantes, Éditions Hispaniques, Paris, 2005, p. 340.

24. «Las mozas, que no estaban hechas á oír semejantes retóricas, no respondían palabra. »

25. Diálogo de la lengua, Madrid, Clásicos Castellanos, 1964, p. 115.

26. D.C.E.L.C., s.. v. Yantar.

27. Une fois explicitement (quoi que) et une autre par explicitation (je m'en accommoderais), car l'un comme l'autre de ces tours impose que l'on se représente (comme cualquiera) plusieurs éléments et qu'on les accepte tous, ou plutôt n'importe lequel, sans préférence.

28. Cf. Molière, Sgan., 7 : «Cependant arrivé, vous sortez bien et beau, // Sans prendre de repos ni manger un morceau. »

29. Furetière (Dict. Univ.) ne connaît que la construction «active » et Littré, qui enregistre le pronominal, ne trouve à citer aucun exemple.

30. Cf. G. Moignet, Le pronom personnel français. Essai de psycho-systématique historique, Paris, éd. Klincksieck, 1965, chap. VII, p. 145-149.

31. J. Corominas, D.C.E.L.C., s. v. Yantar.

32. « ... vous y trouverez Vostre mere qui s'y dejeune.» (Mir. nonne, 1345, 349).

- «Comment ? Esse tout? Tout le mesnaige est bien pugny : Il n'y a poisson ne demy Dont ung chat se peust desjeuner.» (Myst. Pass. Troyes B, a. 1482, 961). - « ... il vit et apperceut laquelle dite Marguerite qui se desjeunoit seule en une taverne, avec laquelle il se desjeuna. » (Reg. crim. Chât., I, 1389-1392, 205). - «Et encore en i avoit biaucop en la ville, qui se desjunoient et buvoient par les tavernes à la grenace, à le malevissie chiés les Lombars, et rien ne paioient. " (Froissart, Chroniques R, X, c. 1375-1400, 117). « Mais tous, par contrainte, statut rigoureux, amplement et copieusement, baisloient, se desjeunoyent de baisler.» (Rabelais, Pantagruel, V, 27, Paris, Librairie Garnier Frères, 1926, p. 288). - « La plus querelleuse reformation theologienne de quoy le monde se soit desjeuné il y a long temps... » (Montaigne, Essais, IV, 128).

33. Cf. M. F. Delport, "Observations sur la syntaxe du possessif en espagnol médiéval», Permanences et renouvellements en linguistique hispanique. Actes du be Colloque de Linguistique hispanique, Toulouse 18-19 mars 1994, CRIC, Univ. de Toulouse-le-Mirail, 1996, p. 217-227.

34. Cf. « ... car aultre attente // Ne me sçauroit mieulx assouvir, // Veu que j'ay (pour honneur suivir) // Pensée, Grand Amye \& Tante » (C. Marot, Euvres poétiques, t. I, Paris, Classiques Garnier, éd. de G. Defaux, 1990, « Rondeaux », XL, p. 158).

35. Cf. « Je vy tousjours riche, sain \& joyeux // Combien qu'à tort il m'ayt faict grand dommage // Depuis quatre ans. » (C. Marot, op. cit., p. 146).

36. Cf. « Quant est du Cueur, du tout je le te laisse, // Ce nonobstant que me fasses mourir // Avant mes jours. »(C. Marot, op. cit., p. 137).

37. Cf. "Talent, ancien mot pour volonté » (H. Estienne, Précellence, éd. Faugère). Cf. aussi : « Talent : a aussi signifié quelquefois, Volonté [...] \& ce sens s'est conservé encore dans le mot de maltalent, qui signifie mauvaise volonté." (Furetière, Dicc. Univ.). Cf. Enfin: "Ce vous vient de mauvais talent // Nourry en couraige felon. » (C. d'Orléans, Ball. 43).

38. Cf. «Je n'ay desir ne autre affaire // Fors que mon service vous plaise.» (A. Chartier, La Belle dame sans mercy, Lille-Genève, Librairie Giard-Librairie E. Droz, 1949, p. 12, vv. 277-278). - « Tout cela ne sert de riens, fors // A plus indigner la nature // de Fortune. »(C. Marot, op. cit., p. 148). - 
« N'escriptz plus rien en Ryme mesurée // Fors que tu es une Main bien heurée, // D'avoir touché celle qui est tant digne // D'avoir le pris. » (Ibid., p. 143, vv. 12-15).

39. Cf. «Et je ne puis par devers vous aller.» (C. Marot, op. cit., X, v. 3, p. 136).

40. Cf. E. Huguet, Mots disparus et vieillis, Genève, Librairie Droz, 1967, p. 83-84 : « Pour exprimer l'idée de remettre en mémoire, le verbe le plus usité aujourd'hui est rappeler. La langue du XVI siècle avait le même verbe, et en outre ramentevoir, recorder, remembrer : "L'empereur Maurice ... escrivit à Childebert des lettres pleines de courroux, et luy ramenteut ses promesses." (Fauchet, Antiquitez, IV, 11) - "Vous sçavez ce qu'avez à dire ? - Il ne me le fault recorder." (Larivey, la Vefve, I, 4). - "Le tentateur cauteleux luy remembra... la defense sur ce faicte." (Rabelais, III, 33)».

41. Cf. «Fortune a voulu que je tiengne // Ma vie en vostre mercy close. » (A. Chartier, op. cit., p. 19, vv. 453-454).

42. Cf. «Quant est du corps, vray est que meurdry l'as. » (C. Marot, op. cit., t. I, p. 96, v. 40).

43. Cf. «Je seuffre mal ardant et chault // Dont je muir pour vous bien vouloir, // Et si voy qu'il ne vous en chault, // Et n'avez d'y penser vouloir. » (A. Chartier, op. cit., p. 9, vv. 193-194).

44. "Il le tient chier et garde bien // Et ne le chace ne deboute. // Et je qui ay m'entente toute // En vous, sans faintise et sans change, // Suy rebouté plus bas qu'en soute // Et moins privé qu'ung tout estrange.» (A. Chartier, op. cit., p. 16, vv. 387-392).

45. Cassou repousse le verbe retenu par Oudin (endure pour souffre), mais la volonté d'« archaïser » est claire lorsqu'il le postpose au complément : comparer $7 a$ et $7 i$.

46. Incriminer, ignoré de Furetière, n'est attesté dans le dictionnaire de l'Académie que depuis 1835 (cf. T.L.F.). On relèvera, par ailleurs, que le reprochar de l'original, sans objet direct, a gêné. Ce mot, tardivement emprunté au français, appartenait au vocabulaire de la "chevalerie ». Le souvenir de «Bayard, le Chevalier sans peur et sans reproche", aurait pu faire qu'on s'en avise plus souvent. « [Reproche] entró como término caballeresco, según muestra esta crónica [Crón. de Juan II] [...] El verbo reprochar conservó también este resabio caballeresco. [...] Con el mismo carácter entró reprotxar en cat., donde ya es frecuente en Tirante el Blanco.» (J. Corominas, D.C.E.L.C.). Conséquence : plusieurs traducteurs le gomment et le noient dans la traduction du mandarme qui lui fait suite (cf. $7 c:$ m'imposant ; $7 e$ et $7 \mathrm{f}:$ m'ordonnant) ; quatre autres le transforment ( $7 a$ : blâmer ; $7 d$ : repousser ; $7 g$ : chasser ; $7 \mathrm{~h}$ : incriminer). Seul Oudin ( $7 i)$, qui en a encore en ce sens le maniement, le conserve.

47. Le Misanthrope, I, 1 : «Non, l'amour que je sens pour cette jeune veuve // Ne ferme point mes yeux aux défauts qu'on lui treuve ».

48. Sur cette question, voir J. C. Chevalier-M. F. Delport, L'horlogerie de saint Jérôme (Problèmes linguistique de la traduction), Paris, L'Harmattan, 1995, chap. II, p. 32-36.

49. Voir à ce propos J. C. Chevalier, : « Variation sur la toile (De l'histoire de l'esp. tela) », Chréode $\mathrm{n}^{\circ}$ 2, vol. 1, printemps 2009, Paris, Éditions Hispaniques (à paraître).

50. P. Corneille, Le Cid, I, 6 : «Percé jusques au fond du cœur // D’une atteinte imprévue aussi bien que mortelle... »

51. Cf. C. Marot, op. cit., t. I, XI, p. 137 : «Avant mes jours mort me fault encourir // Par un regard, dont m'as voulu ferir. "

52. Cf. A. Chartier, op. cit., « Ballades », IX, p. 54 : «Son doulz regart qui le mien ransonnoie // Me naffre a mort et si m'offre alejance. »-C. Marot, op. cit., XXIV, p. $146:$ «... Ont fait tomber sur moi maint orage : // Mais l'ung des deux m'a navré en courage // Trop plus que l'autre, \& en bien plus de lieux. »

53. Cf. E. Huguet, Mots disparus ou vieillis, Genève, Librairie Droz, 1967, p. 175 : « player, blesser en faisant une plaie.» - Cf. aussi G. de Lorris et J. de Meun, Le Roman de la Rose, Paris, Honoré Champion, t. I, 1983, p. 30, v. 953 : «qui de cele fleiche est plaiez.» À quoi on ajoutera M. Scève, Délie, CCCXI, Paris, Bibliothèque de la Pléiade, 1964, p. 178 : «Assés ne t'est d'avoir mon cœur playé, // Mais tout blessé le tenir en destresse.» 
54. Cf. G. de Lorris et J. de Meun, op. cit., p. 72, vv. 2315-2316 : « soupirs et pointes et friçons, // qui poignent plus que herisons. »- Cf. aussi J. Du Bellay, « Sonnets de l'honneste amour », VII, in Poètes du XVIe siècle, Paris, Bibl. de la Pléiade, p. 415 : « De son autre arc doucement furieux // La poincte d'or justement descochée... »

55. Cf. C. Marot, CEuvres poétiques, t. II, éd. cit., « Epistres », VI, p. 80, vv. 2-4 : « ... croyra, que mon absence // Vient par sentir la coulpe, qui me poingt // D'aulcun meffaict. » - XII, vv. 52-53, p. 101 : «Il est bien vray que c'est chose establye // De mettre à fin le desir qui me poingt.» - Chants divers, III, vv. 5-6, p. 187 : « Non pour touts deux en bataille vous joindre, // Ne par fureur de voz lances vous poindre. »-Amyot, Les vies parallèles des hommes illustres, "Alexandre-le-Grand, XV » : "Ceste parole poignit Philippus au vif et luy fist recognoistre sa faulte. »

56. Cf. A. Chartier, op. cit., XLI, vv. 321-323, p. 14 : « De tant plus que Dieu et nature // Ont fait plaisirs d'amour plus hault, // Tant plus aspre en est la pointure.»- J. Du Bellay, op. cit. : «Les premiers traicts de sa doulce rigueur // Mieux figurant la mort de sa vigueur, // qu'imaginant le vif de sa poincture. »

57. Cf. A. Chartier, op. cit., I, vv. 4-6: «Le plus dolent des amoureux, // Puis que, par son dart rigoureux, // La mort me toulit ma maistresse... »-C. Marot, op. cit., t. I, XXIV, vv. 1-3, p. 146 : « Depuis quatre ans faulx Rapport vitieux, // Et de la mort le dard pernicieux // ont faict sur moy tomber maint grand orage.»- J. Du Bellay, op.cit., VII, p. 415 : «Le sainct brazier de mon affection, // Ne darde en bas les saints traiz de sa flamme. »

58. Cf. C. Marot, op. cit., t. I, XXV, vv. 6-9, p. 147 : «Enfans nourriz de sa gausche mamelle, // Composons luy (je vous prie) ung libelle, // Qui picque dru, \& qui morde à loisir // Faulse Fortune. "

59. Souvenir de l'espagnol tollido (« Lo mismo que quitar. Es voz antiquada. » - Aut.).

60. Cf. C. Marot, op. cit., t. I, XLIX, vv. 6-9, p. 164 : «Car en tous lieux tousjours t'ay estimée, // Et si on dict, que je t'ay deprimée, // Je dy que non, et le veulx maintenir // Jusque à la mort ». Cf. aussi E. Huguet, L'évolution du sens des mots, op. cit., p. 216-217 : « Deprimer exprimait aussi l'idée de rabaisser en paroles : Ce qu'ils ne pourront nier et ne le voudront neantmoins confesser, ils le deprimeront de paroles, et se gaussans tascheront de le renverser par une oblique risée. Le Loyer, Hist. des Spectres, I, 2. Aujourd'hui déprimer peut avoir encore un sens concret et un sens abstrait, mais dans l'un comme dans l'autre, l'idée d'abaisser s'est presque effacée. »

61. Cf. A. Chartier, op. cit., p. 30, vv. 711-712 : «Car venteur n'est a honnorer, // Puis que sa langue le desprise.", et p. 51, IV Balade : "Disant : 'Desir, il me plaist que tu t'armes // Contre cellui qui desprise mes dars.' »

62. Cf. J. de Valdés, op. cit., p. 105 : "Quando yo hablo o escrivo, llevo cuidado de usar los mejores vocablos que hallo, dexando siempre los que no son tales. Y assí no digo [...] asaz, sino harto.» Cf. aussi : « Es voz antígua y de algun uso. » (Aut.).

63. Cf. Oresme, Prol. : « Ceulx ici mesmes profitassent plus assez en telles besongnes, se avecques la bonne abilité de nature que ilz ont, ilz eussent la doctrine. » - Froissart, Les chroniques de sire J. F., I, 1, 31 : « Ils les haioient plus assez que les Escots. »

64. Cf. C. Marot, op. cit., t. I, XXIV, vv. 4-5, p. 146 : « Mais l'ung des deux m'a navré en courage // Trop plus que l'autre, \& en bien plus de lieux. »- LV vv. 5-6, p. 168-169 : « Trop plus qu'en aultre en moy s'est arresté // Fascheux ennuy. »

65. E. Huguet, L'évolution..., op. cit., p. 204.

66. Cf. Froissart, op. cit., II, III, 60 : «Anglois sont hastifs et orgueilleux sur les champs, Portingallois chauds et bouillans et tantost entrepris de paroles; ni ils ne sont pas trop souffrans .»

67. Cf. A. Chatier, op. cit., "Rondelet", VIII, vv. 1-4, p. 53 : «Riche d'espoir et povre d'autre bien, // Comblé de dueil et vuidé de liesce, // Je vous suppli, ma loyale maistresse, // Ne me toulez ce que je tiens pour mien.» - Ibid., XVI, vv. 9-13 : «Tout bien ou tout mal m'en yra. // Car quant vostre bouche dira // Oy ou nenny seulement, // Elle asserra le jugement // Dont mon dueil ou 
moy finera.» - Cf. aussi C. Marot, op. cit., t. I, «L'adolescence Clementine », XXVIII, vv. 13-15, p. 149 : «Mais sans bouger va en obscure sente // Cacher mon dueil affin que mieux appere, // En esperant.»-XXX, vv. 1-3, p. 150 : «Dueil, ou plaisir me fault avoir sans cesse : // Dueil quand je voy (ce jour plein de rudesse) // Mon Redempteur pour moy en la croix pendre. »

68. Cf. C. Marot, op.cit., t. I, vv. 8-9, p. 168 : «S'il te plaisoit luy faire cest honneur // Tant seulement. »

69. Cf. A. Chartier, op. cit., « Ballades», XI, vv. 5-6, p. 55 : « Non chaloir veuil desormais hebergier // Avec oubly pour moy donner secours. "

70. Cf. A. Chartier, op. cit., «La Belle dame...", XXVI, v. 204, p. 9 : «Je suy vostre et vostre me tien. "

71. Cf. A. Rosenblat, op. cit., p. 116-130.

72. Cette séquence réapparaît au chapitre XXX (Clás. Cast., t. III, p. 105) : « ... a los caballeros andantes no les toca ni atañe averiguar si los afligidos, encadenados y opresos... "

73. La Belle dame sans mercy, op. cit., p. 12, v. 277-278: «Je n'ay desir ne autre affaire // Fors que mon service vous plaise. »

74. Cf. A. Chartier, op. cit., p. 11, v. 261-262 : «Et puis qu'ainsi m'est escheu // D'estre a mercy entre vos mains..."

75. Cf. A. Chartier, op. cit., p. 9, v. 205-207 : « De droit je n'y chalenge rien // Car ma volenté s'est submise // En vostre gré, non pas au mien. »

76. Ed. Clásicos Castellanos, t. I, chap. II, p. 80.

77. Sur cette publication et la correspondance de Paul Valéry avec le colonel Godchot, voir Paul Valéry vivant, « Cahiers du Sud», Marseille, MCMXLVI, p. 373-376.

\section{RÉSUMÉS}

Tous les textes du passé sont archaïques par leur langue, et cet archaïsme par force, jusqu'à aujourd'hui, a été sensible aux lecteurs de toutes les époques postérieures à celle de leur publication. Mais le Don Quichotte offre à cet égard une particularité : celle d'inscrire dans ce premier archaïsme un second, celui des tournures syntaxiques et lexicales mises dans la bouche du héros principal. C'est là une difficulté supplémentaire imposée aux traducteurs. Sont examinées et commentées ici les réactions face à ce problème, et durant presque quatre siècles, d'une dizaine de traducteurs français. Leurs réactions, les diverses solutions adoptées et quelques propositions qui pourraient leur être opposées.

Language is archaic in all texts of the past, and this archaism inevitable; it was sensible to readers of all times after the publication of the texts, up to now. 'Don Quixote' is yet particular in this respect: it inscribes a second archaism in the first one, consisting in the syntactic and lexical turns of phrase put in the mouth of the main character, which is a supplementary difficulty imposed on translators. The reactions of a set of ten French translators to this problem, throughout almost four centuries, are examined and commented here: their reactions, the diverse solutions they adopted and a few propositions which could be opposed to them.

Todos los textos del pasado por su lengua son arcaicos, y ese arcaísmo hasta hoy, forzosamente, ha sido sensible a los lectores de todas las épocas posteriores a la publicación. Pero el Quijote a este respecto ofrece una particularidad : la de introducir dentro de este primer arcaísmo un 
segundo, el de los giros sintácticos y léxicos del héroe principal. Es ésta una dificultad suplementaria que se impone a los traductores. Se examinan y comentan aquí las reacciones frente a este problema, y durante casi cuatro siglos, de unos diez traductores franceses. Sus reacciones, las diversas soluciones adoptadas y algunas propuestas que pudieran oponérseles.

INDEX

Mots-clés : traduction, Don Quichotte, archaïsmes, lexique, syntaxe

\section{AUTEURS}

JEAN-CLAUDE CHEVALIER

Paris IV - Sorbonne

MARIE-FRANCE DELPORT

Paris IV - Sorbonne 